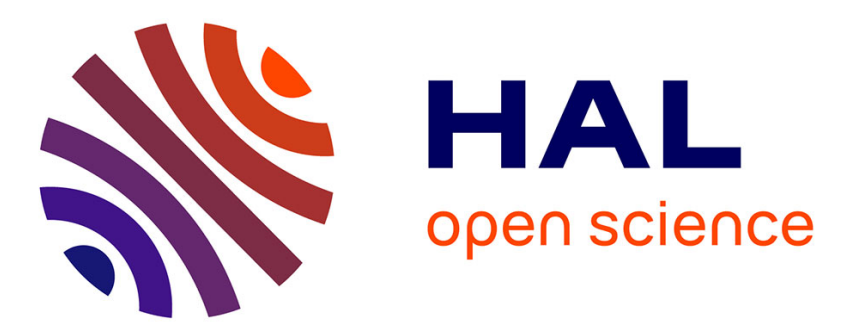

\title{
The early development of brain white matter: A review of imaging studies in fetuses, newborns and infants
}

Jessica Dubois, Ghislaine Dehaene-Lambertz, Sofya Kulikova, Cyril Poupon, Petra S. Hüppi, Lucie Hertz-Pannier

\section{- To cite this version:}

Jessica Dubois, Ghislaine Dehaene-Lambertz, Sofya Kulikova, Cyril Poupon, Petra S. Hüppi, et al.. The early development of brain white matter: A review of imaging studies in fetuses, newborns and infants. Neuroscience, 2014, 276, pp.48-71. 10.1016/j.neuroscience.2013 . hal-02433855

\section{HAL Id: hal-02433855 \\ https://hal.science/hal-02433855}

Submitted on 9 Jan 2020

HAL is a multi-disciplinary open access archive for the deposit and dissemination of scientific research documents, whether they are published or not. The documents may come from teaching and research institutions in France or abroad, or from public or private research centers.
L'archive ouverte pluridisciplinaire HAL, est destinée au dépôt et à la diffusion de documents scientifiques de niveau recherche, publiés ou non, émanant des établissements d'enseignement et de recherche français ou étrangers, des laboratoires publics ou privés. 


\title{
The early development of brain white matter: A review of imaging studies in fetuses, newborns and infants
}

Jessica Dubois Ph.D. ${ }^{1}$, Ghislaine Dehaene-Lambertz M.D. Ph.D. ${ }^{1}$, Sofya Kulikova M.S. ${ }^{2,3}$, Cyril Poupon Ph.D. ${ }^{4}$, Petra S. Hüppi M.D. Ph.D. ${ }^{5,6}$, Lucie Hertz-Pannier M.D. Ph.D. ${ }^{2,3}$

Affiliations:

1: INSERM, U992, Cognitive Neuroimaging Unit, Gif-sur-Yvette, France; CEA, NeuroSpin Center, Gif-sur-Yvette, France; University Paris Sud, Orsay, France

2: INSERM, U663, Paris, France; CEA, SHFJ/NeuroSpin Centers, Gif-sur-Yvette, France; University Paris Descartes, Paris, France

3: CEA, NeuroSpin Center, UNIACT, Gif-sur-Yvette, France

4: CEA, NeuroSpin Center, UNIRS, Gif-sur-Yvette, France

5: Geneva University Hospitals, Department of Pediatrics, Division of Development and Growth, Geneva, Switzerland

6: Harvard Medical School, Children's Hospital, Department of Neurology, Boston, MA, USA

Corresponding author:

Jessica Dubois, $\mathrm{PhD}$

CEA/SAC/DSV/I2BM/NeuroSpin/Cognitive Neuroimaging Unit U992

Bât 145, point courrier 156

91191 Gif-sur-Yvette, France

Email: jessica.dubois@centraliens.net

Neuroscience 2014. 276:48-71.

\begin{abstract}
Studying how the healthy human brain develops is important to understand early pathological mechanisms and to assess the influence of fetal or perinatal events on later life. Brain development relies on complex and intermingled mechanisms especially during gestation and first post-natal months, with intense interactions between genetic, epigenetic and environmental factors. Although the baby's brain is organized early on, it is not a miniature adult brain: regional brain changes are asynchronous and protracted, i.e. sensorymotor regions develop early and quickly, whereas associative regions develop later and slowly over decades. Concurrently, the infant/child gradually achieves new performances, but how brain maturation relates to changes in behaviour is poorly understood, requiring noninvasive in vivo imaging studies such as MRI.

Two main processes of early white matter development are reviewed: 1) establishment of connections between brain regions within functional networks, leading to adult-like organisation during the last trimester of gestation, 2) maturation (myelination) of these connections during infancy to provide efficient transfers of information. Current knowledge from post-mortem descriptions and in vivo MRI studies is summed up, focusing on T1- and $\mathrm{T} 2$-weighted imaging, diffusion tensor imaging, and quantitative mapping of T1/T2 relaxation times, myelin water fraction and magnetization transfer ratio.
\end{abstract}




\section{Keywords}

Brain development, white matter pathways, (bundles), organization, (maturation), myelination, magnetic resonance imaging MRI, diffusion tensor imaging DTI, (relaxometry, myelin water fraction MWF, fetus, preterm newborn, infant).

\section{Table of contents}

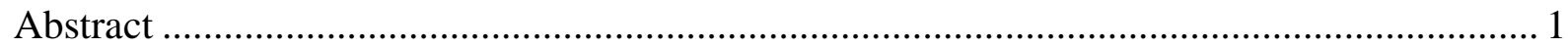

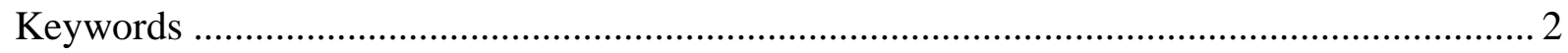

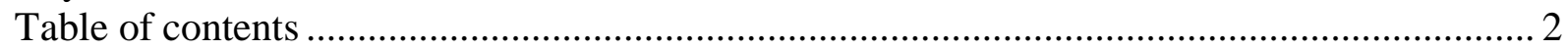

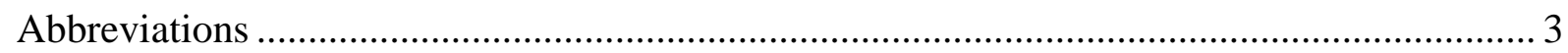

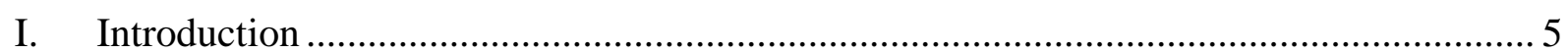

II. The basic concepts of white matter development ...................................................... 6

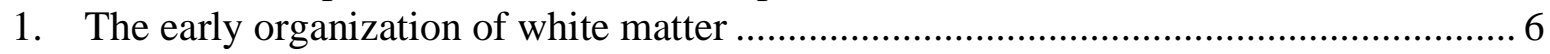

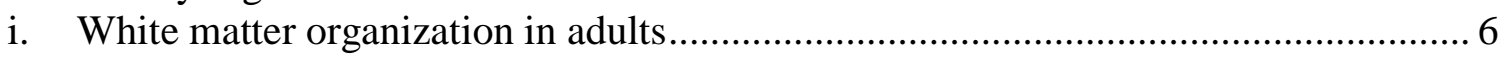

ii. Growth of fiber connections during the last trimester of gestation ......................... 6

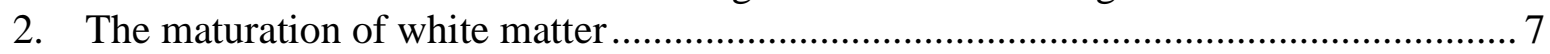

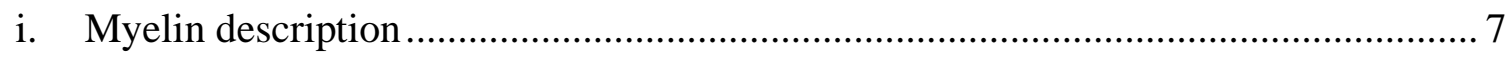

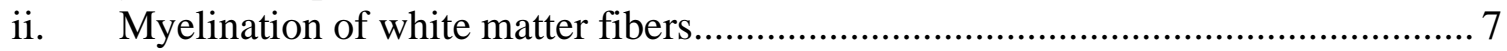

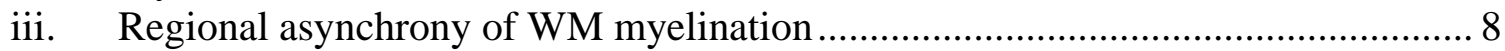

iv. Functional correlates of WM myelination ......................................................... 8

III. Structural MRI techniques and developmental specificities .................................... 9

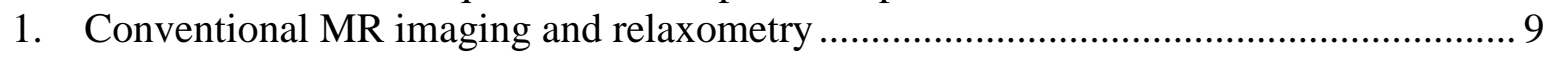

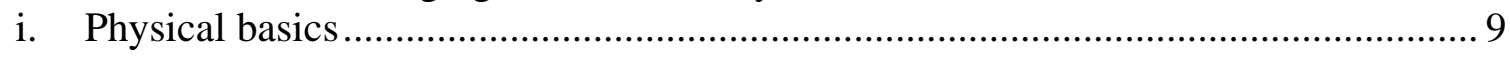

ii. Developmental specificities of $\mathrm{T} 1 \mathrm{w}$ and $\mathrm{T} 2 \mathrm{w}$ contrasts ..................................... 9

iii. Mapping T1 and T2 relaxation times during WM maturation.............................. 10

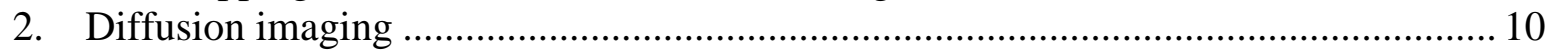

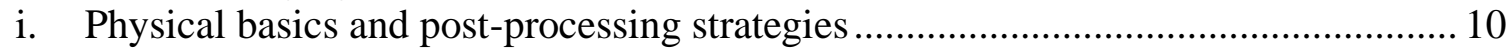

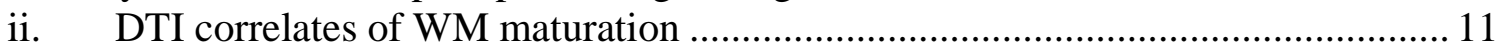

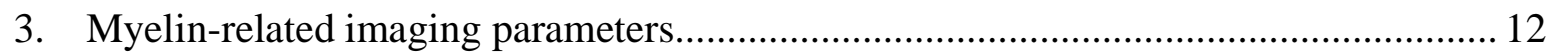

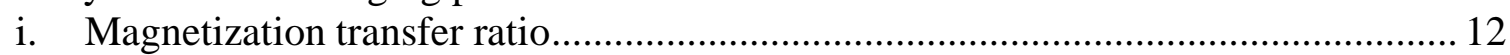

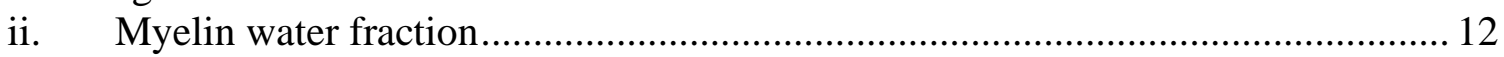

4. Practical considerations for imaging the developing brain ........................................ 13

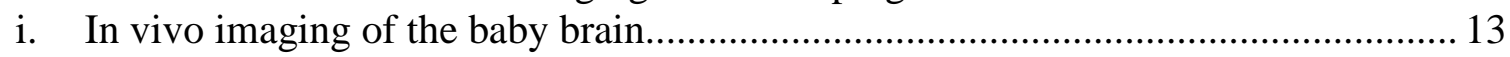

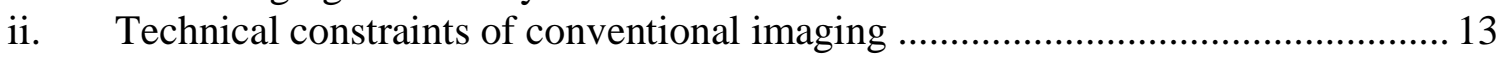

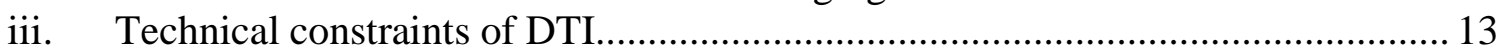

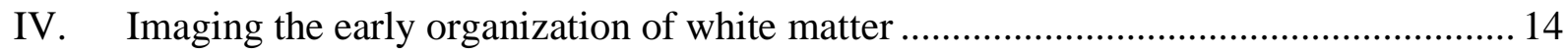

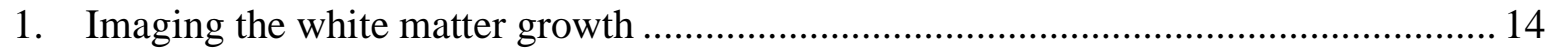

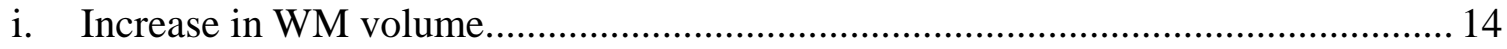

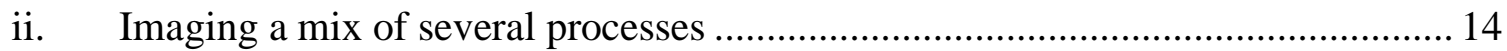

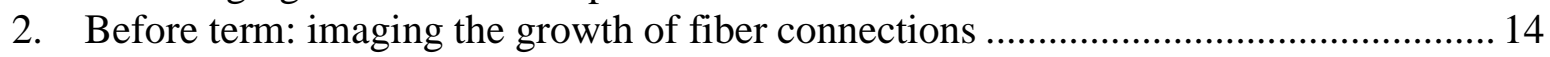

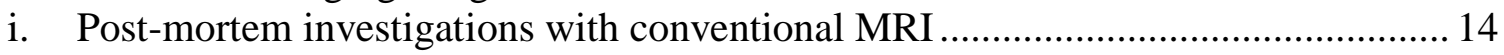

ii. Post-mortem investigations with diffusion imaging ......................................... 15

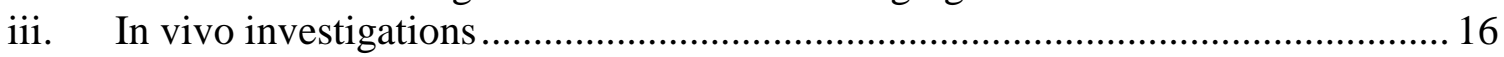

3. After term: imaging the WM bundles and developing connectivity .......................... 16

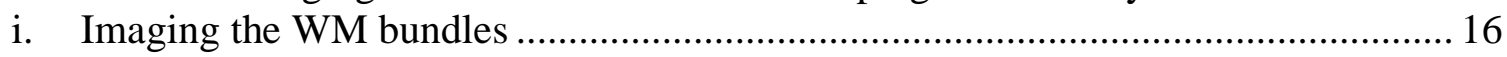

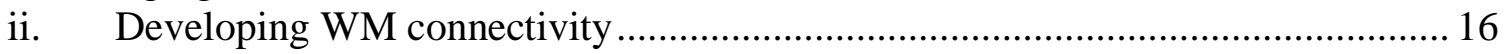

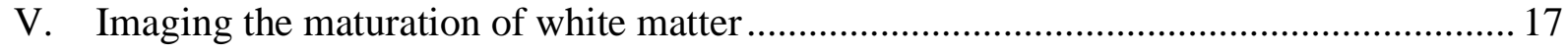

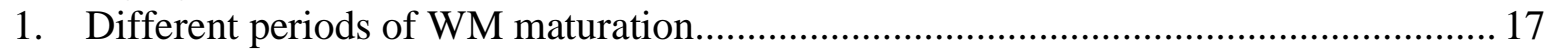

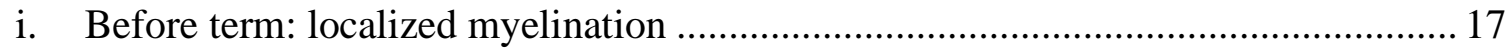


ii. After term: major changes related to myelination .............................................. 17

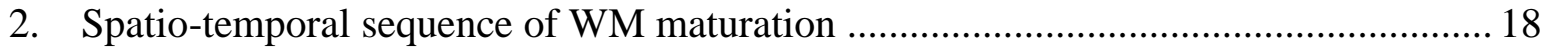

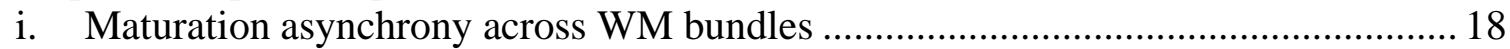

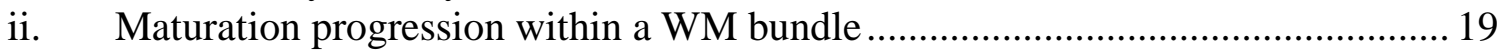

3. Sophisticated approaches to map WM maturation asynchrony .................................... 19

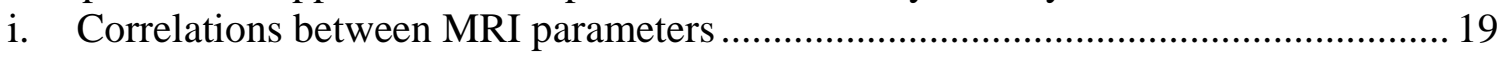

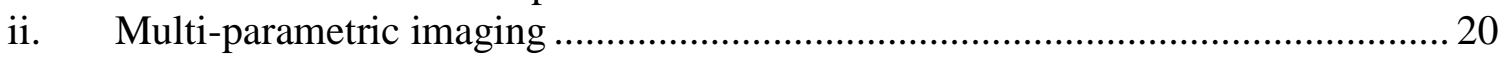

VI. Functional correlates of MRI biomarkers of WM maturation .................................. 21

1. Early WM asymmetries in highly lateralized functional networks ............................ 21

2. Correlations between DTI parameters and functional measurements .......................... 21

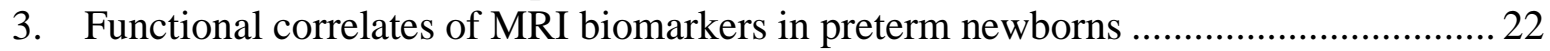

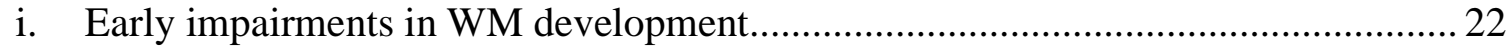

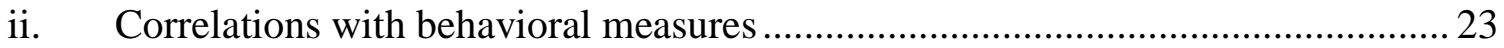

iii. Focus on the developing visual system............................................................ 23

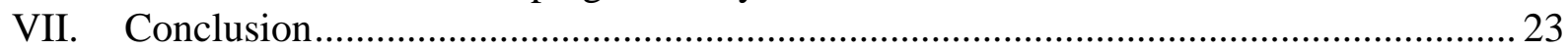

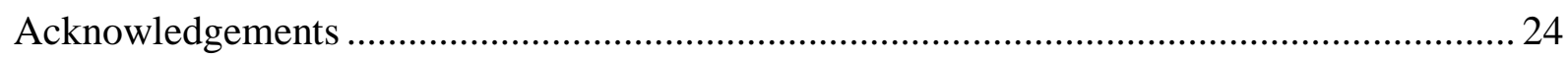

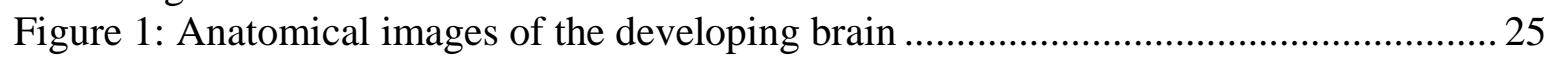

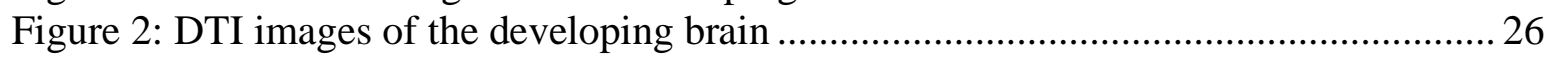

Figure 3: Tractography of the developing white matter bundles .................................... 27

Figure 4: Illustrations of maturation-related changes in MRI parameters ........................... 28

Figure 5: Age-related changes in white matter volume and DTI parameters ...................... 29

Figure 6: Age-related changes in quantitative parameters related to myelin ....................... 30

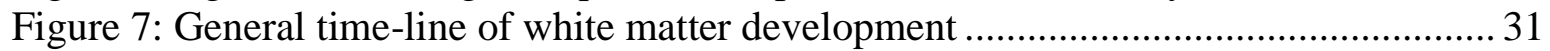

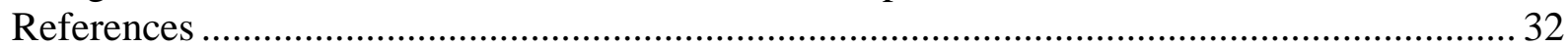

\section{Abbreviations}

$\begin{array}{ll}\text { AF } & \text { arcuate fasciculus } \\ \text { ALIC } & \text { anterior limb of the internal capsule } \\ \text { CC } & \text { corpus callosum } \\ \text { CG } & \text { cingulum } \\ \text { Cl } & \text { linear diffusion anisotropy } \\ \text { CNS } & \text { central nervous system } \\ \text { Cp } & \text { planar diffusion anisotropy } \\ \text { CS } & \text { centrum semiovale } \\ \text { CST } & \text { cortico-spinal tract } \\ \text { DEHSI diffuse excessive high signal intensity } \\ \text { DTI } & \text { diffusion tensor imaging } \\ \text { DWI } & \text { diffusion-weighted imaging } \\ \text { EC } & \text { external capsule } \\ \text { FA } & \text { fractional anisotropy } \\ \text { GA } & \text { gestational age } \\ \text { GM } & \text { grey matter } \\ \text { ILF } & \text { inferior longitudinal fasciculus } \\ \text { MD } & \text { mean diffusivity } \\ \text { MRI } & \text { magnetic resonance imaging } \\ \text { MTR } & \text { magnetization transfer ratio } \\ \text { MWF } & \text { myelin water fraction } \\ \text { OR } & \text { optic radiations } \\ \text { PD } & \text { proton density }\end{array}$


PLIC posterior limb of the internal capsule

PTA post-term age: post-natal age corrected for gestational age at birth, considering a term age of $40 \mathrm{w}$

PVWM peri-ventricular white matter

$\mathrm{R} 1$ relaxation rate associated with $\mathrm{T} 1$ relaxation time $(\mathrm{R} 1=1 / \mathrm{T} 1)$

$\mathrm{R} 2$ relaxation rate associated with $\mathrm{T} 2$ relaxation time $(\mathrm{R} 2=1 / \mathrm{T} 2)$

SNR signal-to-noise ratio

STT spino-thalamic tract

TBSS tract-based spatial statistics

TE echo time

TI inversion time

TR repetition time

T1 longitudinal relaxation time

T1w T1-weighted

T2 transverse relaxation time

T2w T2-weighted

UF uncinate fasciculus

VLBW very-low-birth weight

WM white matter

2D 2 dimensions

3D 3 dimensions

$\lambda_{/ /} \quad$ longitudinal diffusivity

$\lambda \perp \quad$ transverse diffusivity 


\section{Introduction}

Brain development relies on several complex and intermingled mechanisms, such as the maturation and functional specialisation of grey matter (GM) regions (cerebral cortex and central grey nuclei) and the establishment and myelination of white matter (WM) connections between the different neural regions. Typical development is the global consequence of interactions between genetic programming, epigenetic and environmental factors (e.g. external stimulations, maternal, nutritional or medical factors). Cerebral changes are particularly intense during the last weeks of gestation and the first post-natal months, as indirectly highlighted by the non-linear increase of the cranial perimeter (by about $14 \mathrm{~cm}$ during the two first post-natal years, followed by only $7 \mathrm{~cm}$ until adulthood). Although the baby's brain is organized early on into functional networks, it is not an adult brain in miniature: growth and maturation are asynchronous, some regions, like the sensory ones, develop early on and quickly, whereas associative regions, like frontal ones, develop later on and slowly until the end of adolescence (Paus, et al. 2001).

Concurrently with this anatomical evolution of the brain, the infant gradually achieves new psycho-motor and cognitive skills, but how brain maturation explains the often abrupt changes of behaviour observed during development is poorly understood. Before the development of non-invasive brain imaging methods, our knowledge on human brain development was relying on (fortunately) rare post-mortem investigations, which are intrinsically limited by the lack of anatomo-functional correlations and by the uncertainty on brain normality. Using myelin staining, most of these studies described whether myelin is present or not in a given WM region at a given age: this information is however not bundlespecific and thus might be misleading at bundles crossings. Advanced post-mortem dissection techniques now enable to follow the trajectory of long-distance bundles (Maldonado, et al. 2013; Martino, et al. 2010). But absolute measurements of myelin amount are still missing, which prevents the quantitative comparison across WM regions.

Another approach to understand brain development is to study animals, but if such studies enable to test particular hypotheses, they remain largely inadequate because of the specificity of human cognitive functioning and brain development. Mammals are generally classified according to their developmental stage at birth, belonging either to species with early development or to species with immature development. Humans have a special position since brain responses are already observed in utero (Draganova, et al. 2007), while some high-level functions have a protracted development over two decades. For instance, he fiber myelination in the somatosensory, motor, frontopolar and visual neocortices is delayed in humans compared with chimpanzees, with slower myelination during childhood extending beyond late adolescence (Miller, et al. 2012).

The recent development of non-invasive techniques (magnetic resonance imaging MRI, electroencephalography EEG, magnetoencephalography MEG) has further enabled to relate maturation of cerebral structures to infants' neurodevelopment and behaviour. In particular, several MRI techniques available on clinical scanners (section III) enable to investigate and follow longitudinally the brain development and plasticity of healthy and atrisk children (Barkovich 2000; Huppi and Dubois 2006; Neil, et al. 2002; Paus, et al. 2001; Prayer and Prayer 2003; Yoshida, et al. 2013). But when these imaging techniques are applied to babies, many difficulties arise and require adapting data acquisition and post-processing to different developmental periods (fetus, preterm or at-term newborn, infant, toddler, etc.).

With these constraints in mind, we here review the main insights revealed by recent MRI studies on the early development of white matter, which is a complex and long-lasting process that plays a crucial role during the human motor and cognitive development (section II). Two main stages can be delineated: 1) the establishment of long and short connections between 
brain regions during the last trimester of human gestation, leading to an early adult-like organisation of neural networks, 2) the maturation of these fibers during infancy and toddlerhood to provide an efficient transfer of information between functional regions. These two processes are consecutively described in the healthy brain by summarizing current knowledge obtained from post-mortem and in vivo imaging studies (sections IV and V). Finally, the functional significance of early structural biomarkers of the developing white matter is discussed based on studies with behavioural and neurophysiologic evaluations of infants, with a specific focus on preterms without overt brain lesions (section VI).

\section{The basic concepts of white matter development}

\section{The early organization of white matter}

\section{i. $\quad$ White matter organization in adults}

White matter contains a large amount of glial cells (astrocytes, oligodendrocytes and microglia, which account for around 50\% of the total brain volume and nearly $90 \%$ of brain cells), but it is mainly studied as the brain compartment of crossing paths that connect different functional regions. Long-distance fibers, generally gathered into bundles, can be classified according to their connection patterns. Commissural fibers connect the two cerebral hemispheres, mostly between homotopic regions (e.g. the corpus callosum). Projection fibers are bi-directional fibers between the thalamus and the cortex, between the cortex and the brainstem and spinal cord (e.g. the cortico-spinal tract, the optic radiations). Associative fibers regroup cortico-cortical fibers between intra-hemispheric regions (e.g. the arcuate fasciculus) and fibers of the limbic system (e.g. the fornix).

\section{ii. $\quad$ Growth of fiber connections during the last trimester of gestation}

The progressive organization of WM connections has been established with post-mortem studies. Once the neuron has migrated to its final localization, it develops connections with other neurons at both ends: a dendritic tree within the grey matter, and the formation of an axon running through the white matter. At the macroscopic level, the axons formation leads to the formation of long-distance bundles. This wiring occurs mostly during the second part of pregnancy, but its exact temporal progression is still poorly described in humans. It includes processes of neuronal and synaptic overproduction, followed by cellular apoptosis, axonal retraction and synaptic pruning. All these processes of overproduction/elimination are essential to sustain the functional networks plasticity (Stiles and Jernigan 2010). The early wave of migrating neurons remains in the subplate (underneath the future cortex) and is crucial to establish a first rough blueprint of the cerebral organization, both for the cortex and the white matter. On the one hand, they relay thalamo-cortical projections in the late fetal and preterm brain, amplifying sensory signals (Kanold and Luhmann 2010; Kostovic and Judas 2010), and on the other hand they send pioneering axons toward the internal capsule to guide axons from the later migrating neurons (McConnell, et al. 1989). They also guide interhemispheric connections through the corpus callosum between 25 and 32 weeks of gestational age (w GA) (deAzevedo, et al. 1997).

To reach their target structure, axons grow and are guided by their extremity growth cones, which are attracted or repulsed by positive or negative signals (e.g. contact signals, chemical signals, neuro-transmittors, growth factors). They follow "pioneering" axons (process of "fasciculation"). The initial connection production stage is followed by a pruning stage that aims at suppressing redundant or aberrant circuits and is dramatically sensitive to the environment (Huttenlocher and Bonnier 1991). This process may be influenced by several 
factors: e.g. neuron survival, competition for trophic factors, electrical activity of axons, afferent inputs. In particular, in the corpus callosum, pruning is a major morphogenetic process between the end of gestation and the first and second postnatal months (Innocenti and Price 2005). In the rhesus monkey, up to $70 \%$ of callosal axons are eliminated in the four first post-natal months (LaMantia and Rakic 1990). In humans, the number of axons in the corpus callosum may be close to a maximum in the newborn brain (with no new axons being formed to cross the midline), and the process of axonal pruning is supposed to occur after birth (Kostovic and Jovanov-Milosevic 2006).

\section{The maturation of white matter}

Concurrently and subsequently to the organization of WM networks, fiber connections become progressively mature and functionally efficient through the myelination process that favors the conduction of the nervous impulse (Baumann and Pham-Dinh 2001; Van der Knaap and Valk 1995; Van der Knaap and Valk 1995b).

\section{i. $\quad$ Myelin description}

In the adult brain, the WM white color is due to the high myelin content (40 to 50\% of dry weight). The myelin sheaths enwrapped around axons are complex bilamellar membranes constituted by lipoproteins (myelin basic proteins MBP, proteo-lipid proteins PLP, myelin associated glycoproteins MAG, 2',3'-Cyclic nucleotide-3'-phosphohydrolase CNP, etc.) and lipids (cholesterol, phospholipids, glycolipids, galactocerebrosides, etc.). This "roll-cake like" structure is formed by the membrane prolongations of oligodendrocytes in the central nervous system (CNS) (Barkovich 2000).

The myelin role is to allow a fast conduction of the nerve impulse. Indeed, the action potential propagates along the axon by electrical depolarization of the nervous membrane, continuously when no myelin sheath enwraps the axon, or via saltatory conduction from a Ranvier node to the next (Ranvier nodes are the fiber places between myelin sheath segments). The conduction speed depends on the distance between nodes, on axonal diameter and on the myelin sheath thickness: from $2 \mathrm{~m} . \mathrm{s}^{-1}$ in unmyelinated CNS fibers to $120 \mathrm{~m} \cdot \mathrm{s}^{-1}$ in myelinated fibers of the peripheral nervous system.

\section{ii. $\quad$ Myelination of white matter fibers}

Myelination (i.e. myelin formation around axons) is the last stage of white matter development, that begins after the process of axonal overproduction-pruning and follows premyelinating stages including the formation and maturation of oligodendrocytes (Thomas, et al. 2000). This process includes several steps (Butt and Berry 2000; Hardy and Friedrich 1996; Prayer and Prayer 2003). Oligodendrocyte precursors proliferate, migrate and form "initiator" processes, which align along axons (predominant radial orientation) and identify targeting axons (Volpe 2008). Spiral ensheathment around the axon starts with an extension of such a process that elongates and wraps around the axon. Afterward, the myelin sheath becomes more compact, through an increasing number of spiral turns that is determined by the axonal diameter (Baumann and Pham-Dinh 2001).

A single oligodendrocyte myelinates several axons (even of different diameters), suggesting that each axon participates to the regulation of its myelination (Friede 1972). In the human brain, four stages of oligodendrocyte maturation have been described: early and late progenitor cells, immature and mature oligodendrocytes. The immature oligodendrocytes (which are multipolar cells rich in a lipid called galactocerebroside) account for 30 to $40 \%$ of the entire oligodendroglia population in the preterm period ( 28-37w GA).

The "pre-myelinating" state generally refers to the initial period when preoligodendroglial cells increase and settle along the axons (Baumann and Pham-Dinh 2001), 
and when the cholesterol and glycolipids concentration starts to increase (Barkovich, et al. 1988; Poduslo and Jang 1984). The following "true" myelination process corresponds to the ensheathment of oligodendroglial processes around the axons, and to the chemical maturation of the myelin sheath with rising amount of macromolecules (Barkovich, et al. 1988; Poduslo and Jang 1984). At the microscopic level, the myelination induces major changes in water molecules content and compartmentalization (Matsumae, et al. 2001) and in protein and lipid contents (Barkovich, et al. 1988; Kucharczyk, et al. 1994). Notably, a strong correlation exists between myelination and the concentration of galactocerebroside in immature and mature oligodendrocytes (Matthieu 1993).

\section{iii. Regional asynchrony of WM myelination}

Myelination occurs in the human brain from the second part of pregnancy to the end of adolescence. A peak is observed during the first post-natal year. Its progression varies across cerebral regions: it follows a caudo-rostral gradient and progresses from the center to the periphery. Post-mortem studies have detailed this sequence (Brody, et al. 1987; Flechsig 1920; Gilles, et al. 1983; Kinney, et al. 1988; Yakovlev 1962; Yakovlev and Lecours 1967), using a visual ordering from stages 0 to 4 according to staining with hematoxylin and eosinluxol fast ("mature myelin" refers to stages 3 and 4). Some myelin is observed microscopically from 20w GA on at the level of the bulb and pons, which are myelinated at birth. Mature myelin is detected from 37-40w GA in the cerebellum and internal capsule. Between the first and third post-natal months, the posterior limb of the internal capsule, the optic radiations and the corpus callosum splenium become myelinated. Mature myelin can be found from the $6^{\text {th }}$ month in the anterior limb of the internal capsule and in the corpus callosum genu, from the $15^{\text {th }}$ month in the occipital pole, and from the $23^{\text {rd }}$ month in the frontal and temporal lobes (for review (Baumann and Pham-Dinh 2001).

From these post-mortem studies, several rules can be outlined on the myelination progression in the brain (Kinney, et al. 1988): it occurs earlier and faster 1) in proximal pathways than in distal ones; 2) in sensory pathways (somatosensory, vision, audition) than in motor ones; 3 ) in projection fibers than in associative ones; 4) in central regions than in polar ones; 5 ) in the occipital pole than in the posterior parietal white matter and in the temporal and frontal poles. These global schemes cannot be dissociated from one another, and suggest eight sub-groups of maturation, depending on the presence/absence of myelin at birth (subgroups A/B) and the time periods at which mature myelin is observed (sub-groups 1-4) (Kinney, et al. 1988). For example, the middle cerebellar peduncles, the optic tract and chiasm, the posterior limb of the internal capsule, the cortico-spinal tract in the midbrain and pons and the central corona radiata belong to sub-group A1; optic radiations (proximal and mid-distal), auditory radiations (proximal), the corpus callosum body and splenium belong to sub-group B1; cingulum, external capsule, the anterior limb of the internal capsule, the corpus callosum rostrum and Heschl's gyrus belong to sub-group B2; fornix and extreme capsule belong to sub-group B4. This asynchrony in the maturation sequence is supposed to depend on the hierarchy of connections between cortical areas (Guillery 2005): the early maturation of receptive sensory areas (responsible for low-level processing) would enable a stabilization of the information used by integrative areas (involved in high-level processing) which develop later on.

\section{iv. Functional correlates of WM myelination}

Beside glial factors, neuronal maturation and electrical activity might control myelination induction (Kinney, et al. 1988). Blocking this activity in vitro inhibits myelination (Demerens, et al. 1996), and the proliferation of oligodendrocytes precursors is influenced by neighboring axonal activity (Barres and Raff 1993). Electrical activity in the mouse optic nerve influences 
the triggering of myelination over a short time period (Demerens, et al. 1996). This nerve myelination is further delayed in mice kept in a dark environment after birth (Gyllensten and Malmfors 1963) and accelerated in rabbits whose eyelids have been opened prematurely (Tauber, et al. 1980). Astrocytes may act as an intermediary between myelination and electrical impulse activity, through the mediation of a cytokine leukemia inhibitory factor (Ishibashi, et al. 2006). Nowadays, the inhibitory role of oligodendrocytes and myelin on neuritic growth is also considered, which may partly explain the weak plasticity of the adult brain (Ng, et al. 1996).

Since myelination leads to a spectacular increase in the conduction speed of the nerve impulse (Baumann and Pham-Dinh 2001), it is assumed to improve the functional efficiency of brain networks (van der Knaap, et al. 1991). Myelination of the midbrain and spinal cord is actually coupled with behavioral improvement (Langworthy 1928; Langworthy 1928b), but fiber myelination and functional maturation are uncorrelated in different cerebral systems. For instance, the myelination of the cortico-spinal tract occurs before birth in several regions (midbrain, internal capsule, central corona radiata) while the newborn motor capacities are weak. On the other hand, the acoustic radiations have an extended myelination until 3 years of age while the infant auditory system is efficient early on.

Such discrepancy may rely on the fact that extending myelination may be necessary in a second step to compensate for brain growth and maintain similar latencies between brain regions across ages (Salami, et al. 2003). In the visual system for example, the latency of the first positive wave of response to a stimulus (P1) reaches the adult latency ( 100ms) at around 4 post-natal months, whereas the distance between the retina and the calcarine fissures still increases by around $6 \mathrm{~cm}$ until adulthood. Whereas the transfer of visual information may be efficient early on in 4-month old infants, an extending myelination may enable to further increase the conduction speed by around $0.6 \mathrm{~m} . \mathrm{s}^{-1}$ in relation with brain growth.

\section{Structural MRI techniques and developmental specificities}

Several complementary MRI techniques can be used to image brain development in healthy infants. Since signal comes from the hydrogen nuclei (the "protons") of water molecules, cerebral tissues with different water concentrations and environments demonstrate on MR images different contrasts that change with brain maturation.

\section{Conventional MR imaging and relaxometry}

\section{i. $\quad$ Physical basics}

"Conventional" MRI generally refers to images whose signal is weighted (noted "w") by proton density or by relaxation times, which characterize how fast the water magnetization returns to equilibrium after the perturbation induced by electromagnetic waves. The longitudinal relaxation time (T1) characterizes the proton interactions with its environment ("spin-lattice" interactions), while the transverse relaxation time (T2) characterizes the interactions between protons ("spin-spin" interactions). In the developing brain, T1 weighting is generally obtained with short TR and short TE, or using inversion recovery sequences with long inversion times (TI), while T2 weighting is obtained with long repetition times (TR) and long echo times (TE). Since relaxation times depend on tissue characteristics, T1w and T2w images demonstrate high contrast between cerebral tissues in the adult brain (Figure 1).

\section{ii. $\quad$ Developmental specificities of T1w and T2w contrasts}

Because of brain tissues immaturity and high water content, T1w and T2w contrasts are very different in the infant brain from what is described in the adult brain, and contrasts 
evolve with brain maturation (Figure 1). Considering the brain as a whole, successive maturational stages are described (Paus, et al. 2001): (1) the infantile pattern (0-6 months), showing a reversal of the normal adult contrasts (T1w: lower WM intensity than GM intensity; T2w: higher WM intensity than GM intensity); (2) the iso-intense pattern (8-12 months), characterized by a poor contrast between GM and WM; and (3) the early-adult pattern (>12 months) (T1w: higher WM intensity than GM intensity; T2w: lower WM intensity than GM intensity). Actually, the specific time-course of these patterns depends on brain regions because of maturation asynchrony (see section $\mathrm{V}$ ).

As a consequence, the delineation between the grey and white matter is often not obvious on infant images, contrarily to the clear border observed on adult $\mathrm{T} 1 \mathrm{w}$ images. T1 weighting is mostly used during the preterm and perinatal periods, but the contrast becomes poorer with age until it recovers during the second post-natal year. T2 weighting transitorily enables a better contrast between term and 4-6 months post-term (Leroy, et al. 2011b). The second postnatal semester is actually the most difficult period to image, with a weak delineation of the GM/WM border.

To identify myelinated WM regions from unmyelinated regions, T1w contrast is generally preferred during the first 6-8 post-natal months, and T2w contrast between 6 and 14 months because changes in white matter contrasts are observed on T1w images before T2w images (Barkovich, et al. 1992; van der Knaap and Valk 1990).

\section{iii. $\quad$ Mapping $T 1$ and $T 2$ relaxation times during WM maturation}

The changes observed on $\mathrm{T} 1 \mathrm{w}$ and $\mathrm{T} 2 \mathrm{w}$ contrasts can be used to understand maturation processes, but $\mathrm{T} 1 \mathrm{w}$ and $\mathrm{T} 2 \mathrm{w}$ signals cannot be directly compared across individuals because of the variability between exams related to technical tunings. To provide such inter-individual comparisons, either signals may be normalized for each subject in reference to a given tissue (e.g. the cortico-spinal fluid) (Leroy, et al. 2011a), or T1 and T2 relaxation times may be quantitatively measured (Figure 1) by recording signals from dedicated MRI acquisitions with different sequence parameters (e.g. different inversion times TI to compute T1, different echo times TE to compute T2).

In the developing brain, T1 and T2 decrease more strongly in WM than in GM because of myelination processes (Figure 4a) (Barkovich 2000; Prayer and Prayer 2003). At least two distinct pools of water molecules are supposed to contribute to MR signal in the white matter: water located within the myelin sheath (with relatively short $\mathrm{T} 1$ and $\mathrm{T} 2$ relaxation times) and intra-axonal, intra-cellular and interstitial water (i.e. water outside of the myelin sheath, with longer T1 and T2). Both $\mathrm{T} 1$ and $\mathrm{T} 2$ decreases parallel the decrease in water concentration, nevertheless their time courses are different, and two distinct mechanisms can be distinguished: the change in water molecules compartmentalization (Matsumae, et al. 2001), and the increase of protein and lipid contents (Barkovich, et al. 1988; Kucharczyk, et al. 1994). T1 shortening starts already during the "pre-myelinating" state, while T2 shortening correlates temporally with the chemical maturation of the myelin sheath (Barkovich, et al. 1988; Baumann and Pham-Dinh 2001; Poduslo and Jang 1984) (Figure 4c).

\section{Diffusion imaging}

\section{i. $\quad$ Physical basics and post-processing strategies}

Another recent approach to assess WM maturation is diffusion-weighted imaging (DWI) which measures the natural motion of water molecules. The diffusion in cerebral tissues is not "free" (Le Bihan 2003). Microscopic displacements may be restricted within multiple physical compartments, or hindered by cell and organelle membranes: this results in tortuous pathways around these obstacles. Imaging diffusion at the macroscopic scale thus 
enables to explore the tissue microstructure non-invasively (Le Bihan, et al. 2001). To take into account the spatial heterogeneity of the diffusion process, the diffusion information is generally encoded in different spatial directions, and the diffusion tensor (DT) formalism is used with the assumption that a single fiber orientation is present in each voxel of the image and that the diffusion process can be represented by an ellipsoid that encodes the tensor eigenvectors and eigenvalues. The DTI technique provides maps of quantitative and complementary parameters (Figure 2): diffusion anisotropy (e.g. fractional anisotropy FA) (Beaulieu 2002), mean diffusivity (MD = one third of the tensor trace), longitudinal diffusivity $\left(\lambda_{/ /}=\right.$diffusivity along the main tensor axis) and transverse diffusivity $(\lambda \perp=$ diffusivity perpendicular to the main axis).

The trajectory of white matter fibers can be further reconstructed virtually in 3 dimensions (3D) using tractography algorithms that follow the direction of the main DT eigenvector from a voxel to a neighbouring voxel (Le Bihan and Johansen-Berg 2012) (Figure 3 ). The dissection of major WM bundles is then based either on the individual definition of regions crossed by the fibers, or through automatic classifications recently proposed for the adult brain, such as clustering (Guevara, et al. 2012; Guevara, et al. 2011) and probabilistic methods (Yendiki, et al. 2011). Recently, some alternatives to the tensor model have been proposed, such as Q-ball imaging, diffusion spectrum imaging (DSI) and high-angular resolution diffusion imaging (HARDI). These techniques enable to resolve multiple fiber orientations within a voxel, but they require long acquisition times hardly achievable in vivo in healthy unsedated infants.

\section{ii. DTI correlates of WM maturation}

DTI parameters are well suited to reveal information that is not apparent on T1w and T2w images during brain development (Figure 2) (Huppi and Dubois 2006; Neil, et al. 2002). It is generally assumed that diffusivities decrease with maturation, while anisotropy increases in the developing white matter (Huppi, et al. 1998a; Neil, et al. 1998) and decreases in the cortex during the preterm period (Ball, et al. 2013; McKinstry, et al. 2002). Transverse diffusivity decreases more in WM than in GM (Mukherjee, et al. 2002), leading to a reversed contrast between newborns and adults on transverse diffusivity maps. In WM bundles, changes are more intense for transverse than for longitudinal diffusivity (Dubois, et al. 2008b; Geng, et al. 2012; Mukherjee, et al. 2002), with even no change in longitudinal diffusivity detected after 1 year of age (Gao, et al. 2009). These parameter dynamics in WM bundles are consistent with the assumption of a cylindrically symmetric decrease in diffusion due to myelination process (Mukherjee, et al. 2002).

Fifteen years ago, it had been suggested that the age-related decrease in mean diffusivity in both grey and white matter would reflect the overall decrease in brain water content, while the increase in anisotropy in the white matter would rather rely on its microstructure (e.g. packing and myelination) (Neil, et al. 1998). Nowadays the current hypotheses on the relationships between these parameters and the maturational mechanisms are recognized as more complex in the white matter (Figure $4 b$ ).

Even in the absence of myelin, the tight organization of WM fibers inside a bundle lead to intrinsic anisotropy related to high longitudinal diffusivity contrasting with low transverse diffusivity (Beaulieu 2002). Studies in rat pups have shown that the first evidence of anisotropy precedes initial myelin (Wimberger, et al. 1995), and that this early anisotropy may be related to sodium-channel activity (Prayer, et al. 2001).

During the first stage of myelination ("pre-myelination"), when glial cell bodies and membranes proliferate, both a decrease in brain water content and an increase in membrane density are observed, which imply decreases in mean, longitudinal and transverse diffusivities. Whereas this mechanism had initially been assumed spatially isotropic (Dubois, 
et al. 2008b), recent evidence rather suggests that the initial extension of oligodendroglial processes is anisotropic in favor of the axonal direction (Nossin-Manor, et al. 2012; Zanin, et al. 2011). This anisotropy increase has been related to the maturation of the compound action potential and the development of immature oligodendrocytes in the rabbit developing white matter (Drobyshevsky, et al. 2005).

The following "true" myelination process (with the ensheathment of oligodendroglial processes around the axons) is further accompanied by a decrease in both membranes permeability and extracellular distance between membranes, implying an increase in anisotropy, a decrease in transverse diffusivity, but no change in longitudinal diffusivity. At crossing fibers places, the situation may appear puzzling when crossing bundles follow different maturational calendars: when the first bundle gets myelinated, anisotropy first increases, but it subsequently decreases when the second crossing bundle gets mature (the reverse argument has been detailed for neurodegenerative disorders (Douaud, et al. 2011)); at the same time, diffusivities are decreasing (Figure $4 b$ ).

Therefore anisotropy and longitudinal diffusivity are rather good markers of tissue macrostructure and organization, finely characterizing compactness, crossing fibers, etc. but the interpretation of their changes may remain difficult during WM maturation. On the contrary, transverse diffusivity consistently decreases with all maturational processes (Figure $4 c)$.

Recently, other geometrical diffusion measures (linear and planar diffusion anisotropies $\mathrm{Cl}$ and $\mathrm{Cp}$ ) have been considered to model more accurately different WM microstructures in comparison with the classical cylindrical shape of a fiber bundle (Chen, et al. 2011). During maturation, these parameters may be sensitive to changing compactness since after birth $\mathrm{Cl}$ growth velocities are highest in central white matter while $\mathrm{Cp}$ growth velocities are highest in peripheral white matter.

Finally, let's keep in mind that DTI parameters vary across bundles in the adult brain, in relation with their macroscopic geometry and compactness. Highlighting maturational effects in the developing brain thus requires either considering the developmental trajectories toward adulthood to evaluate the asymptotes of maturation, or normalizing infant measurements by the adult references (Dubois et al. 2008a).

\section{Myelin-related imaging parameters}

Other quantitative parameters relying on the myelin amount have been proposed to evaluate the maturation of white matter.

\section{i. $\quad$ Magnetization transfer ratio}

The "magnetization transfer ratio" (MTR) informs about the ratio between free water and water with restricted motion, bound to macromolecules such as proteins and lipids (McGowan 1999). Thus it is thought to reflect the myelin amount and increase during WM maturation (Kucharczyk, et al. 1994). Nevertheless, during the preterm period (26-34w GA), MTR values have been found higher in the genu and splenium of the corpus callosum (CC) than in the posterior limb of the internal capsule (PLIC) and the periventricular white matter (PVWM). Since at this stage callosal fibers are highly organized, closely packed, but nonmyelinated fibers, this technique appears to be sensitive not only to myelin-associated macromolecules, but also to the macromolecular density of axonal cytoskeleton components such as microtubules and neurofilaments (Nossin-Manor, et al. 2012) (Figure 4c).

\section{ii. $\quad$ Myelin water fraction}

As for approaches based on "multi-component relaxation" (MCR) analyses, different pools of water molecules are modeled in each voxel (Spader, et al. 2013). These pools can be 
distinguished from measured MR signals, on the basis of different relaxometry properties (T1 and/or T2) and of specific exchange relationships (Beaulieu, et al. 1998; Menon, et al. 1991; Whittall, et al. 1997). Such decomposition is supposed to provide valuable information on the tissue microstructure. Whereas the exact number of pools to be modelled is still debated (Deoni, et al. 2012b), a consistent pool of water related to myelin is always considered, and studies generally describe maps of "myelin water fraction" (MWF) (Figure 1). This fraction drastically increases during WM maturation (Deoni, et al. 2012a) (Figure 4c). Contrarily to relaxation times, the definition of MWF is a priori independent from the magnetic field. But its computation is highly sensitive to both the acquisition protocol and the post-processing modeling, making direct comparisons across studies hardly achievable.

\section{Practical considerations for imaging the developing brain}

\section{i. In vivo imaging of the baby brain}

The pre- and post-term periods are radically different, not only in terms of brain organization (see next section) but also in terms of practical possibilities to obtain MR images. Because infants after term are generally healthy, ethical and practical issues are similar to older ages. On the contrary, the main difficulty in imaging the pre-term period is to obtain images of healthy (or at least not neurologically ill) brains. Imaging fetuses in utero is not commonly done without strong medical arguments. Similarly, preterm newborns are at high-risk of neurological lesions, and their physiological stage is very unstable making them difficult to move to MRI center without good reasons.

In all cases, imaging fetuses and infants is a challenge. Data are difficult to acquire first because of the techniques' sensitivity to motion. Without clinical indication, healthy babies cannot be sedated, then one cannot prevent a fetus to move within the womb, and quietness is difficult to obtain in infants during a long time. Thus, data acquisition should remain short, especially in preterms in whom it is difficult to maintain a stable thermal state inside the MR scanner. Acoustic noise should also remain reasonable, in order to avoid any acoustic trauma and discomfort, and to assure baby's sleep or quiet cooperation. Second, despite short acquisition time, image spatial resolution should be higher than in adults because cerebral structures are smaller. That is why the scarce images obtained at early ages (i.e. before 5 months of gestation) have been obtained in post-mortem fetuses with very long acquisition times.

\section{ii. Technical constraints of conventional imaging}

The developing brain is changing every day, much more rapidly than the adult brain between 20 and 50 years of age, and $\mathrm{T} 1 \mathrm{w}$ and $\mathrm{T} 2 \mathrm{w}$ contrasts change with the brain tissues maturation. This contrast variability and the use of different MR sequences along the first post-natal year require dedicated post-processing tools for different developmental periods to segment unmyelinated and myelinated white matter from other cerebral tissues (grey matter, cerebro-spinal fluid). However it may lead to misclassification of cerebral tissues (Choe, et al. 2012; Matsuzawa, et al. 2001), and the comparison across ages remains difficult.

\section{iii. $\quad$ Technical constraints of DTI}

The signal-to-noise ratio (SNR) of DW images decreases with infants' age because both $\mathrm{T} 2$ relaxation times and diffusivities decline during the first post-natal months (Mukherjee, et al. 2002). Actually the reliability of DTI estimation is influenced by SNR and by the number of diffusion directions. To a certain extent, acquiring more directions is equivalent to averaging (Dubois, et al. 2006a). Adapting the number of diffusion directions according to the infants' age (with more numerous directions in older infants) is worth 
considering to make the data reproducible across subjects. Furthermore, DTI quantification is particularly sensitive to motion artefacts, and several strategies have been proposed to reduce or correct them during the acquisition (Dubois, et al. 2006b) or in post-processing (Dubois, et al. in revision).

\section{Imaging the early organization of white matter}

\section{Imaging the white matter growth}

\section{i. $\quad$ Increase in WM volume}

With all these difficulties in mind, we can try to appreciate the WM growth by estimating its volume from T1w and T2w images acquired before and after term (Figure 5a). In normally developing fetuses in utero, the global volume of the intermediate zone and subplate (whose frontier remains difficult to delineate) increases from around 15 to $90 \mathrm{~cm}^{3}$ between $21 \mathrm{w}$ and 31w GA, i.e. $15 \%$ per week (Scott, et al. 2011). In premature neonates, the WM volume increases from around $50 \mathrm{~cm}^{3}$ at $29 \mathrm{w}$ GA to $170 \mathrm{~cm}^{3}$ at $44 \mathrm{w}$ GA, as reported in age-specific atlases (Kuklisova-Murgasova, et al. 2011). Afterwards, a longitudinal follow-up study in infants has demonstrated that WM volume increases from around $164 \mathrm{~cm}^{3}$ at term birth to $183 \mathrm{~cm}^{3}$ at 1 year of age (i.e. increase by $11 \%$ per year), to $218 \mathrm{~cm}^{3}$ at 2 years of age (i.e. increase by $19 \%$ per year).

Thus at these ages WM growth is relatively slow in comparison with the rapid GM growth (by $149 \%$ in the first year and $14 \%$ in the second year), leading to a decrease in the percentage of WM when normalized for the total brain volume (Gilmore, et al. 2007; Knickmeyer, et al. 2008). Subsequently the WM volume increases at a higher rate than GM volume throughout childhood (Matsuzawa, et al. 2001), and the ratio between WM and GM volumes dramatically increases during childhood and adolescence (Groeschel, et al. 2010).

\section{ii. Imaging a mix of several processes}

While WM tissue is imaged as a whole on T1w and T2w images, its volume increase actually reflects several processes that occur successively or concomitantly during development, but whose contributions are hard to separate. WM composition is changing dramatically, especially during the mid-gestation period which is marked by neuronal migration: pyramidal neurons follow radial patterns along glial fibers, from the central periventricular region to the cortical periphery, while interneurons follow tangential patterns from the ganglionic eminence. Axonal connections are also growing from central grey nuclei and from cortical regions. Besides, the vascularity is developing according to a radial organization. These coherent structural patterns are mixing, making the dissection of growing fascicles difficult. Concurrently, glial cells proliferate: oligodendrocytes play a crucial role to myelinate axonal fibers during the late pre-term and post-term periods, while the contribution of developing astrocytes and microglia is still poorly understood, notably in terms of metabolism. Overall, several mechanisms contribute to the global increase in WM volume, and more subtle MRI techniques are thus required to detail the axonal organization in the growing WM.

\section{Before term: imaging the growth of fiber connections}

\section{i. $\quad$ Post-mortem investigations with conventional MRI}

Correlation studies between histology and conventional MRI with high spatial resolution in post-mortem fetuses (Judas, et al. 2005; Rados, et al. 2006) have shown that three fiber 
systems are recognizable as early as $12 \mathrm{w}$ GA: the corpus callosum, the fornix and the hemispheric stalk, which represents a massive connection between the telencephalon and the diencephalon and contains all the projection fibers of the developing internal capsule, including the thalamo-cortical fibers. During the mid-fetal period (17-24w GA), a substantial elaboration of major cerebral fiber systems is observed in the "intermediate zone" (the fetal "white matter"). In the fronto-polar and occipito-polar regions, the fiber architectonics of the fetal cerebrum displays a tangential axon strata. Below the corpus callosum, the fornix is well developed. The corpus callosum, the internal and external capsules are growing. In the central white matter, the "periventricular crossroads" are the intersections between these major fiber systems: callosal fibers (transverse direction), associative fibers (sagittal direction), thalamocortical/cortico-fugal fibers (radial direction).

Between 24 and 32w GA, the major events are the development of the corona radiata, from the transformation of the tangential fetal fiber-architectonic stratification. All major segments of the cerebral white matter can be recognized: corpus callosum, corona radiata, centrum semiovale, gyral white matter (which is not yet fully developed because the subplate zone remains interposed between the corona radiata and the cortex). Fibers continue to grow at the levels of the periventricular crossroads and of the ventricular part of the corpus callosum, which leads to a blurring on post-mortem images. By term birth, all major fiber systems are to be in place.

\section{ii. Post-mortem investigations with diffusion imaging}

DTI imaging is an exquisite technique to detail the developing organization of white matter and precise the developmental calendar observed on conventional images. Imaging fetuses post-mortem at 19-20w GA confirmed that limbic fibers (cingulum, fornix) develop first (entire trajectories visible at 19w GA) and association fibers last (Huang, et al. 2006). The corpus callosum, the uncinate and inferior longitudinal fasciculi become apparent between 13 and 22w GA (Huang, et al. 2009). At 20w GA, the corpus callosum formation is more advanced in the frontal lobe (genu and forceps minor) than in other regions (splenium and forceps major, body). The core regions of projection fibers are well-developed early on, but not the peripheral regions (i.e. the corona radiata), and the anterior limb of the internal capsule develops before the posterior limb.

The more elaborated technique of HARDI tractography applied to post-mortem fetuses between $19 \mathrm{w}$ to $42 \mathrm{w}$ GA (Takahashi, et al. 2012) has clarified the calendar of tract development. A few immature long-range association pathways are visible early on in the white matter (e.g. the uncinate and fronto-occipital fascicles), and short-range cortico-cortical tracts emerge prior to gyrification in regions where sulci will later develop. An early dominant radial organization of WM that gradually diminishes by term age is observed. This feature disappears first in dorsal parieto-occipital regions, second in ventral fronto-temporal regions; earlier at the depths of sulci than in the crests of gyri. At $19 \mathrm{w}$ GA, the ganglionic eminence presents a dominant tangential organization which gradually disappears by term. These radial and tangential patterns are related to neuronal migration as confirmed by the combination of HARDI technique with the structural analysis of conventional images in post-mortem fetuses between $21 \mathrm{w}$ and $24 \mathrm{w}$ GA (Kolasinski, et al. 2013). The radial pattern originates in dorsopallial ventricular / subventricular zone, while the tangentio-radial patterns originate in subpallial ganglionic eminence. These patterns regress in a caudo-rostral and lateral-ventral to medial-dorsal direction across this short developmental period. The post-mortem application of immunomarkers to radial glial fibers, axons, and blood vessels has enabled to decipher the histological origins of the HARDI-defined coherence (Xu, et al. 2012), suggesting that the radial coherence in the fetal white matter likely reflects a mixture of radial glial fibers (at mid- 
gestation), penetrating blood vessels (that are consistently radial), and radial axons (among radial, tangential and oblique axons).

\section{iii. In vivo investigations}

Data acquired in vivo in preterms and fetuses have confirmed post-mortem studies. Using diffusion imaging, the early laminar organization of the cerebrum (cortical plate, subplate zone, intermediate zone, subventricular and periventricular zones, germinal matrix) has been delineated in 25-27w GA preterm newborns (Maas, et al. 2004). Imaging studies of in utero fetuses have described that the pyramidal tract and the splenium and genu of the corpus callosum are depicted early on and may be reconstructed in 3D using tractography algorithms between 18 and 37w GA (Bui, et al. 2006; Kasprian, et al. 2008; Pontabry, et al. 2013), as well as the Probst bundles in cases of corpus callosum agenesis (Kasprian, et al. 2013). In preterms, association tracts and subcortical projection tracts are also identified (Dudink, et al. 2007; Partridge, et al. 2004).

\section{After term: imaging the WM bundles and developing connectivity}

\section{i. $\quad$ Imaging the WM bundles}

After term birth, almost all prominent white matter tracts are identified despite low anisotropy values (Hermoye, et al. 2006). This early organization has been further mapped in 3D in infants between 1 and 4 months of age, using a dedicated protocol for acquisition and post-processing (Dubois, et al. 2008b; Dubois, et al. 2006a). Most commissural bundles (genu, body and splenium of the corpus callosum), projection bundles (cortico-spinal tract, spino-thalamic tract, optic radiations, anterior limb of the internal capsule), limbic bundles (fornix and cingulum) and associative bundles (external capsule, uncinate, arcuate, superior and inferior longitudinal fascicles) can be detected and tracked (Figure 3). In a longitudinal study using a dedicated DTI atlas, a similar organization of the major bundles has been shown between newborns and toddlers of 1 and 2 years of age (Geng, et al. 2012).

However, some associative bundles that mature later on (see section V), such as the superior longitudinal fasciculus, demonstrate large changes in fiber orientations during the first post-natal months (Zhang, et al. 2007). High-field imaging at 3T may enable the precise exploration of subtle connections within specific developing networks (e.g. the language network (Dubois, et al. in preparation). Actually one should keep in mind that DTI methodology does not enable to decipher between exact fiber directions in the place of crossing fibers, particularly when crossing bundles are maturing at different rates and over different time periods. This leads to erroneous interpretation on the presence/absence of a bundle in the developing brain. Accordingly, the dorsal pathway of the developing language network (the arcuate fasciculus) may not seem to fully connect temporal and frontal regions in newborns (Brauer, et al. 2013; Perani, et al. 2011), but this might be artefactually related to its low maturation in comparison with the crossing cortico-spinal tract (Dubois, et al. in preparation).

\section{ii. Developing WM connectivity}

Recently, the wiring pattern of cerebral connections and the maturational calendar have been reinterpreted in the framework of small-world topology (Hagmann, et al. 2010). The principal characteristics observed in adults have been found in infants demonstrating that the infant brain is neither fully connected, nor only locally connected (Fan, et al. 2011; Pandit, et al. 2013; Yap, et al. 2011). This result might appear trivial, given the anatomical results reviewed above showing that the short and main long-distance connections are already observed before term, but this approach has the advantage to have no a-priori and to place the 
brain within a mathematical formalism. Longitudinal studies performed from birth to two years of age and based on regional grey-matter volumes (Fan, Shi et al. 2011) and on the number of fibers passing through pairs of regions (Yap, Fan et al. 2011) have been interpreted as showing an increase in integration and a decrease in functional segregation.

Behavioral and functional studies certainly support such hypotheses, but structural studies are confronted with several unsolved drawbacks. For example, the difficulties in GM/WM segmentation vary with age due to changes in $\mathrm{T} 1 \mathrm{w}$ and $\mathrm{T} 2 \mathrm{w}$ contrasts; weakly myelinated fibers may appear shorter because of lower anisotropy that impacts tractography reconstructions; smaller head size creates partial volume effects that might blur connectivity results in younger infants. Finally, network efficiency is sometimes indirectly inferred from diffusion metrics (Hagmann, et al. 2010), and not directly from the transfer times of the neural information, whereas the information propagation at the same latency in the infant and adults brains may not require a similar tract myelination because of the different brain sizes (Salami, et al. 2003). Fortunately, combining these structural measures with electrophysiological and/or resting-state fMRI have indeed shown a strengthening of the correlations between structural and functional connectivities (Hagmann, et al. 2010).

\section{Imaging the maturation of white matter}

When the bundles are in place, a slow process of maturation begins, following a different calendar in different bundles.

\section{Different periods of WM maturation}

\section{i. $\quad$ Before term: localized myelination}

Before 36w GA, unmyelinated WM is the most prominent brain tissue according to T1w and T2w images, and an abrupt increase in myelinated WM is detected between 35 and 41w GA (Huppi, et al. 1998b). However, there is earlier evidence of myelination in specific WM regions (Counsell, et al. 2002) such as the inferior and superior cerebellar peduncles before $28 \mathrm{w} \mathrm{GA}$, the posterior limb of the internal capsule, the cortico-spinal tract around the central sulcus and the corona radiata from 36w GA on.

DTI studies of in utero fetuses (Bui, et al. 2006; Jiang, et al. 2009; Kasprian, et al. 2008; Righini, et al. 2003) and ex utero preterm newborns as young as 26w GA (Aeby, et al. 2009; Aeby, et al. 2012; Dudink, et al. 2007; Huppi, et al. 1998a; Miller, et al. 2002; Neil, et al. 1998) have found the general pattern of age-related decrease in mean diffusivity and increase in anisotropy in different WM regions (pyramidal tract, corpus callosum, frontal and occipital regions). In longitudinal imaging between 28 and 43w GA (Partridge, et al. 2004), early differences have been further identified between several projection and association pathways, with low mean diffusivity and high FA in cerebral peduncles, internal capsule and commissural tracts of the corpus callosum, suggesting an early maturation of these tracts (Figure 5b) and confirming the analyses done on T1w/T2w images.

\section{ii. $\quad$ After term: major changes related to myelination}

After term, WM myelination is intense in the developing brain, and quantitative MRI parameters have underlined successive maturational periods: acute changes during the first post-natal months, less rapid modifications during toddlerhood, and slower changes thereafter until young adulthood. It is particularly obvious for DTI parameters (Figure 5b): decrease in $\mathrm{MD}$ and increase in FA are rapid during the first post-natal year and slower during the second year (Forbes, et al. 2002; Geng, et al. 2012; Hermoye, et al. 2006; Mukherjee, et al. 2001; Sadeghi, et al. 2013). Age-related decreases in diffusivities have been modeled through 
exponential decays from birth to childhood (Mukherjee, et al. 2001), or by a sigmoid function (Gompertz growth function, based on intuitive variables related to delay, speed, and expected asymptotic value) longitudinally from birth to 2 years of age (Sadeghi, et al. 2013).

In the same way, T1 and T2 decreases are particularly rapid over the two first years (Engelbrecht, et al. 1998; Haselgrove, et al. 2000), yielding to exponential decays with age (Figure 6a) (Leppert, et al. 2009). Conversely, the "magnetization transfer ratio" (MTR) increases exponentially (Engelbrecht, et al. 1998; van Buchem, et al. 2001) (Figure 6b). Between 3 and 60 months, the increase in "myelin water fraction" (MWF) is best modelled by a modified Gompertz function which is characterized by four distinct parameters: the developmental lag, the transitionary period and two growth rates (Figure 6c) (Dean, et al. 2013).

To summarize, for all MRI and DTI parameters, the dynamic of changes is intense between birth and two years of age, which does not match the relatively slow increase in WM volume during this developmental period. Furthermore these non-linear patterns of changes reveal considerable regional variations across and along WM bundles because of myelination asynchrony.

\section{Spatio-temporal sequence of WM maturation}

\section{i. $\quad$ Maturation asynchrony across WM bundles}

The interest of DTI studies rests in the quantification of differences across WM bundles, detailing a progression of maturation from a central-to-peripheral and a posterior-to-anterior direction (Oishi, et al. 2011). For instance, the increase in anisotropy appears greater in noncompact ones (corona radiata and peripheral white matter) than in compact white matter structures (corpus callosum, internal capsule, cerebral peduncle) across the first three postnatal years (McGraw, et al. 2002). Diffusivities and anisotropy show different evolutive patterns across brain regions of the preterm brain (Nossin-Manor, et al. 2012) and of the infant brain during the first two post-natal years (Geng, et al. 2012), with highest FA in the corpus callosum and lowest mean diffusivity in the posterior limb of the internal capsule.

By taking advantage of the different sensitivities of diffusivity and anisotropy to maturational processes, a model based on the parameter changes during the "pre-myelination" and the "true" myelination periods was build to describe the bundles maturational stages in infants between 4 and $18 \mathrm{w}$ of post-natal age in comparison with an adult group (Dubois, et al. 2008b). This model enabled to detect early spatio-temporal differences in the maturation progression of a set of bundles, from the more to the less mature bundles: 1) the cortico-spinal tract, 2) the spino-thalamic tract and the fornix, 3) the optic radiations, the arcuate and inferior longitudinal fascicles, 4) the anterior limb of the internal capsule and the cingulum. In a similar way, three distinct phases of maturation, with specific dynamics for each bundle type, have been modeled and identified in the fetal white matter between 23 and 38w GA: i) the axonal organization, ii) the myelination gliosis, and iii) the myelination, which appears early in the cortico-spinal tract, followed by the optic radiations and the corpus callosum (Zanin, et al. 2011).

Regional asynchrony in WM maturation is also observed by MTR, showing a relatively mature stage at $12.9 \mathrm{~m}$ and $15.6 \mathrm{~m}$ in the occipital and frontal white matter respectively, and at $17.7 \mathrm{~m}$ and $18.7 \mathrm{~m}$ in the splenium and genu of corpus callosum (Xydis, et al. 2006). The spatio-temporal pattern of myelination progression is also nicely demonstrated through MWF (Deoni, et al. 2012a; Deoni, et al. 2011). It rises earlier in a frontal-parietal region (projection fibers) than in an frontal region (association fibers) during childhood, following the standard caudal-to-rostral trend (Lancaster, et al. 2003). In infants between 3 and 11 months of age, MWF increases in the cerebellum, pons, and internal capsule; it further 
increases caudo-cranially from the splenium of the corpus callosum and optic radiations (at 34 months); to the occipital and parietal lobes (at 4-6 months); and then to the genu of the corpus callosum and frontal and temporal lobes (at 6-8 months) (Deoni, et al. 2011). The spatio-temporal pattern provided over a larger age range (3 months - 60 months) is coherent with histological studies of myelination (Deoni, et al. 2012a).

\section{ii. $\quad$ Maturation progression within a WM bundle}

The spatial resolution of DTI also allows to studying maturation along a WM tract: maturation does not evolve at the same time and speed in different spatial locations within a bundle (Colby, et al. 2012; Partridge, et al. 2005). During the first two post-natal years, changes near cortical regions generally appear smaller than in brain central regions (Geng, et al. 2012). In preterm newborns between 28 and $43 \mathrm{w}$ GA, the motor tract and the somatosensory radiations of the cortico-spinal tract begin to myelinate during the late preterm period first at the level of the internal capsule (Berman, et al. 2005). Maturation further seems to proceed earlier in the motor pathway than in the sensory one at the vertex where motor fibers initiate from the cortex. From term-equivalent age (Berman, et al. 2005; Geng, et al. 2012), the anisotropy profile presents a local dip at the level of the corona radiata, which suggests the beginning and ongoing maturation of crossing pathways (fibers of the corpus callosum and superior longitudinal fasciculus).

The myelination progression in the visual pathways of infants between 6 and 17w of postnatal age has also been studied, showing two asynchronous fronts of maturation in the optic radiations: an early wave in the anterior region, initiating from the lateral geniculate nucleus, and a later catching-up wave in the posterior region, initiating from the occipital cortex (Dubois, et al. 2008c). According to the assumption that myelination proceeds from the neuron body to the periphery (McCart and Henry 1994), this pattern may result from the respective myelination of the geniculo-cortical (projection) fibers and cortico-geniculate (feedback) fibers, with a delayed maturation of the cortical retrocontrol to the thalamus relative to bottom-up fibers.

\section{Sophisticated approaches to map WM maturation asynchrony}

Recently, original approaches that combine MRI parameters have been proposed to measure even more precisely the maturation across WM regions.

\section{i. $\quad$ Correlations between MRI parameters}

The different parameters (T1, T2, DTI, MTR, MWF) capture different properties of white matter maturation (Figure 4c). Some studies have described specific correlations between them, but most have missed to take into account their major age-related dependencies.

In neonates, a strong correlation has been detected between relaxation rates R1 (1/T1) and R2 (1/T2) among different WM regions (Figure 6a) (Williams, et al. 2005) (Figure 6a). In the kitten WM, DTI mean diffusivity seems to correlate more with R2 than with R1 (Baratti, et al. 1999), whereas maps of mean diffusivity demonstrate a pattern of regional variations similar to T1 maps in preterm newborns between 26 and 45w GA (Nossin-Manor, et al. 2012).

According to the inverse correlation between MTR increase and T2 decrease in WM after term birth, it has been assumed that both changes rely on fast proton relaxation within macromolecules in myelinated tissue (Engelbrecht, et al. 1998). An inverse correlation between MTR and T1 is observed in preterm newborns near term (Nossin-Manor, et al. 2012) (Figure 6b). MTR is also positively correlated with FA in WM during the preterm period, suggesting a coupling between the increase in concentration of pre-myelination-associated macromolecules and the increase in axonal alignment and axonal density (Nossin-Manor, et al. 2012) (Figure 6b). The comparison of MWF measurements with age-related dynamics of 
$\mathrm{T} 1$ (R1) and T2 (R2) relaxation times (rates) has shown that all parameters are sensitive to WM maturation in infants, but in different ways suggesting that they provide complementary information on maturation processes (Deoni, et al. 2012a; Lancaster, et al. 2003) (Figure 6c).

Since T1, T2, DTI, MTR and MWF maps show regional variations following different evolutions with age, these parameters are to be sensitive to multiple and complementary mechanisms of WM development. It is only by combining and comparing these parameters that one can hope to outline comprehensive patterns of the tissue macro- and microstructures. For instance, in preterm infants the corpus callosum displays high values of MTR, T1, FA and longitudinal diffusivity and low transverse diffusivity values, because callosal fibers are highly organized, closely packed, with high axonal density of microstructural components (e.g. microtubules, neurofilaments), leading to high directionality, coherence and restriction, but the fibers are not myelinated and the water content is high (Nossin-Manor, et al. 2012). On the other hand, the posterior limb of the internal capsule shows in the preterm period (premyelinating stage) low values of MTR, FA and diffusivities and high T1 values, resulting from a lower fiber packing density than in the corpus callosum, a lower macromolecular density, along with lower directionality and coherence but higher restriction; at term, the increase in MTR values, along with lower transverse diffusivity, are markers of the myelination process (Nossin-Manor, et al. 2012). Thus a clever use of these different parameters, informed by a better understanding of the mechanisms they are sensitive to, do provide more precise in vivo maps of the WM maturation.

\section{ii. $\quad$ Multi-parametric imaging}

Dealing with multi-parametric data will open new perspectives in the study of WM development. Combining the time trajectories of anisotropy, longitudinal and transverse diffusivities may definitely provide accurate landmarks on maturation asynchrony across bundles (Sadeghi, et al. 2013). Modelling the information from structural (T1w, T2w, proton density images) and DTI data (longitudinal and transverse diffusivities) with modified Legendre polynomials has also provided an absolute measure of maturation (rate of change) and a relative measure (time shift) (Prastawa, et al. 2010). Maps of growth rates demonstrate slow regions (e.g. internal capsule) and rapidly growing regions (e.g. deep white matter in anterior and posterior regions, temporal lobe). Maps of time shifts based on structural data demonstrate gradual changes in regions that undergo myelination, while surprisingly those based on DTI data mostly highlight differences between central and peripheral regions (Prastawa, et al. 2010).

DTI parameters may also be combined with quantitative relaxation times T1 and T2. Because of the complex relations between these parameters in developing bundles (Kulikova, et al. 2013a), an original measure of maturation has been defined in infants between 3 and $21 \mathrm{w}$ of post-natal age to summarize the changes in all parameters while taking into account their possible correlations. This measure, based on the computation of the Mahalanobis distance in comparison with a group of adults, confirms the evidence of WM maturation asynchrony over a short developmental period and outperforms univariate approaches (Kulikova, et al. 2013b). It further provides a quantitative evaluation in weeks of the developmental delays between WM bundles. The maturation order provided by this multiparametric approach during the first post-natal year is congruent with the, from the most to the least mature bundle: the spino-thalamic tract; the optic radiations; 6 weeks later: the middle portion of the cortico-spinal tract and the fornix; 12 weeks later: the inferior portion of the cortico-spinal tract; 7 weeks later: the genu and splenium of the corpus callosum and the superior portion of the cortico-spinal tract; 6 weeks later: the inferior cingulum; 3 weeks later: the corpus callosum body and the superior cingulum; 3 weeks later: the inferior longitudinal, fronto-occipital and uncinate fascicles; 2 weeks later: the external capsule; 3 weeks later: the 
anterior limb of the internal capsule; 4 weeks later: the superior longitudinal and arcuate fascicles literature (Kulikova, et al. in preparation).

\section{Functional correlates of MRI biomarkers of WM maturation}

In healthy infants, WM maturation correlates with psycho-motor acquisitions (Prayer and Prayer 2003) but the exact relationships between cerebral structure and function remain difficult to grasp. Brain anatomical analyses might help to understand the biological bases of cognitive development, by revealing the early structural specificities that may underlie human complex functions such as language, and by mapping correlations between structural indices and functional efficiency. WM studies are also crucial to understand early functional impairments such as the ones triggered by preterm birth.

\section{Early WM asymmetries in highly lateralized functional networks}

Finding which hemisphere is the left one on an axial image of an adult human brain is usually relatively easy thanks to the Yakovlev torque creating right frontal and left occipital petalias, and a steeper and shorter right sylvian fissure (Toga and Thompson 2003). Some of the structural asymmetries observed in the peri-sylvian regions (Heschl gyrus, planum temporale, superior temporal sulcus STS) have been described during the early brain development of fetuses and preterm newborns (Chi, et al. 1977b; Dubois, et al. 2008a; Dubois, et al. 2010a; Feess-Higgins and Laroche 1987). Other asymmetries evolve later on during development: for instance the posterior extension of the sylvian fissure progresses until adolescence and adulthood (Sowell, et al. 2002). At the functional level, the left-hemisphere specialization for language processing is observed early on in infants (Dehaene-Lambertz, et al. 2002; Dehaene-Lambertz, et al. 2006) and already at six months of gestation (Mahmoudzadeh, et al. 2013), and the lateralization of the somato-sensory response is also detected at birth (Erberich, et al. 2006). The origins and relationships between these early anatomical and functional asymmetries are still debated.

Using DTI in healthy infants, three WM regions have been shown asymmetric early on (Dubois, et al. 2009): 1) the temporal part of the arcuate fasciculus is larger on the left; 2) its left parietal part shows a better microscopic organization than the right; 3 ) the cortico-spinal tract is more mature in the left hemisphere between the cerebral peduncles and the posterior limb of the internal capsule. These two bundles have also been shown asymmetric in preterm infants at term-equivalent age (Liu, et al. 2010) and in adults (Buchel, et al. 2004; Parker, et al. 2005). Since these WM pathways are related to language and motor networks, such early structural asymmetries might be biomarkers of the genetic constraints driving development of lateralized functions in the human brain, although no strict correlation has been found between asymmetries of the motor pathways and later handedness.

Myelin content is also asymmetrical in multiple WM regions, with no significant change over time during infancy (O'Muircheartaigh, et al. 2013): toward the left hemisphere in the temporal/occipital lobe on the trajectory of the arcuate and inferior longitudinal fascicles, in the medial frontal and posterior parietal lobes; toward the right hemisphere in the dorsal external/extreme capsule and in central WM. Furthermore, language ability correlates with MWF rightward asymmetry in the external/extreme capsule and with MWF leftward asymmetry in frontal WM, and such relationships seem to stabilize around 4 years of age.

\section{Correlations between DTI parameters and functional measurements}

The key question that encourages further in vivo MRI studies of the developing brain is to which extent advanced structural imaging provides biomarkers of the sensori-motor and cognitive development of infants. In the developing language network, the time course of 
WM myelination parallels language acquisition, with lexical explosion after 18 months of age (Pujol, et al. 2006; Su, et al. 2008). Similar relationships have been highlighted in 12-monthold infants, where visuospatial working memory performance correlated with DTI microstructural characteristics of WM tracts connecting brain regions known to be involved in working memory (genu of the corpus callosum, anterior and superior thalamic radiations, anterior cingulum, arcuate fasciculus), beyond individual variations in age and developmental level (Short, et al. 2013).

Structure-function correlations can also be highlighted by comparing MRI parameters with neurophysiological measures. In the visual system during the first post-natal months, several maturation processes (e.g. fiber myelination, retina and cortex development) lead to a dramatic decrease of the latency of the first response wave to a visual stimulus (P1) as measured by event-related potentials, from about $260 \mathrm{~ms}$ at birth to about $120 \mathrm{~ms}$ at 4 months of age (McCulloch, et al. 1999). This decrease is related to an increase in the conduction speed of the neural impulse, which is correlated to the optic radiations microstructure and maturation (FA and transverse diffusivity) beyond the effect of age (Dubois, et al. 2008c). This correlation study of EEG and DTI measurements (obtained in the same infants) outlines the functional significance of structural markers during WM maturation. The ability to characterize individual anatomical and functional differences across infants is very promising for the understanding of normal development with special focus on experience-dependent mechanisms and critical periods of plasticity. It is also crucial for the definition of biomarkers that will characterize and detect early perturbations of developmental trajectories.

\section{Functional correlates of MRI biomarkers in preterm newborns}

Based on the results obtained in healthy infants, early biomarkers of neurological deficits are searched for, especially in the case of premature birth. The early organization and maturation of axonal pathways is a highly vulnerable process during the second half of pregnancy (Kostovic and Jovanov-Milosevic 2006). In infants born prematurely, brain growth is disturbed by the change from in utero to ex utero environment, and the difficulties to maintain a stable homeostasis. But whereas the neurodevelopmental disabilities of children born prematurely are now rather well described, the underlying alterations of brain development (that lead to disabilities) remain poorly understood (Ment, et al. 2009).

\section{i. $\quad$ Early impairments in WM development}

MRI studies might provide early biomarkers of functional outcome and of specific disturbances of cognitive development. While several reviews have detailed WM abnormalities related to prematurity (periventricular leucomalacia, punctate lesions, diffuse excessive high signal intensity DEHSI) and their long-term effects on the child brain (for example (Ment, et al. 2009; Rutherford, et al. 2010), we here summarize only major findings observed in preterm infants without gross brain lesions and imaged below 2 years of age.

The impact of prematurity on WM development has been mainly evaluated by comparing preterms at term-equivalent age with full-term infants. Preterm infants present with less GM / WM differentiation and myelination in comparison with full-term newborns (Huppi, et al. 1996; Mewes, et al. 2006). The macrostructure of the corpus callosum is impaired, with reduced volume correlating with lower gestational age at birth (Thompson, et al. 2012). Using voxel-based analyses (Rose, et al. 2008) or tract-based spatial statistics (TBSS) (Anjari, et al. 2007), FA reductions were found in several WM regions (centrum semiovale, frontal white matter, corpus callosum, internal and external capsules), but higher FA associated with lower T2 values were also observed in cortico-spinal projections, suggesting a decreased number of crossing inter-hemispheric fibers associated with a decreased water concentration (Rose, et al. 2008). 
Beside white matter, thalamic development is also dramatically disrupted by prematurity, with reduced volume related to abnormalities in "allied" WM structures (cortico-spinal tracts and corpus callosum) at term-equivalent age (Ball, et al. 2012b). The thalamo-cortical loop seems highly vulnerable, with diminished connections between the thalamus and frontal cortices, supplementary motor areas, occipital lobe and temporal gyri in preterm infants (Ball, et al. 2012a). Prematurity is also related to widespread reductions in the connection strength of WM tracts involving all cortical lobes and several subcortical structures during the second post-natal year (Pandit, et al. 2013).

\section{ii. $\quad$ Correlations with behavioral measures}

Local reductions in WM volumes at term-equivalent age in the sensorimotor and midtemporal regions are strongly correlated with measures of cognitive and motor development between 18 and 20 months of corrected age (Peterson, et al. 2003). In the absence of apparent WM lesions, higher mean diffusivity values at the level of the centrum semiovale at termequivalent age have been associated with poorer developmental quotient on the Griffiths Mental Development Scales at 2 years of corrected age (Krishnan, et al. 2007). Similarly, a TBSS analysis has shown that developmental quotient at 2 years corrected age is related to FA in subparts of the corpus callosum at term-equivalent age; performance sub-scores to FA in the corpus callosum and right cingulum; and eye-hand coordination sub-scores to FA in the cingulum, fornix, anterior commissure, corpus callosum and right uncinate fasciculus (Counsell, et al. 2008).

\section{iii. $\quad$ Focus on the developing visual system}

Three studies have focused on the early development of the visual system in preterm infants, because this function matures early on and is frequently impaired by premature birth. Between 29 and 41w GA, the microstructural development (FA) of the optic radiations has been correlated with the newborn visual maturity (scores from a visual fixation tracking assessment) independently of GA (Berman, et al. 2009). This has been confirmed at termequivalent age, with a specific correlation between the visual assessment score and the FA in the optic radiations, independently from GA at birth, GA at scan or presence of lesions on conventional MRI (Bassi, et al. 2008). A recent study has further evidenced an effect of the period of premature extra-uterine life in addition to the degree of prematurity: indeed, visual function around term-equivalent age seems related to FA in the optic radiations at that age, but also to FA evolution pattern, as characterized by the rate of increase between two successive scans (the first between 30 and 36w GA, the second at term-equivalent age between 39 and 46w GA) (Groppo, et al. 2012). The alteration of WM pathways microstructural maturation during the late preterm period thus impacts the visual function at birth.

\section{Conclusion}

Characterizing the dynamics of human brain development and the structural bases of functional maturation requires in vivo studies of the healthy newborn and infant. These studies are challenging and require dedicated methodologies for image acquisition and postprocessing. But it's worth the effort since new quantitative markers of maturation have been recently validated, also providing a better understanding of the deleterious effects of early disturbances such as prematurity.

Mechanisms of white matter development are complex and intermingled. In terms of early WM organization, the growth and wiring of axonal fibers occur mostly during the preterm period, whereas the pruning of aberrant or useless connections rather starts during the first 
post-natal weeks along with external stimulations. Afterwards, fibers get myelinated and progressively functionally mature, which may result from neuronal activity and also reinforce it. WM maturation further impacts on the functional efficiency of brain networks, which correlates with the infant acquisitions. All these mechanisms occur at different times and speeds according to cerebral regions and involved functions, with maturation proceeding until adulthood in some associative frontal and temporal regions. A tentative summary of the timeline of WM development during the preterm period and the first post-natal months can be provided from post-mortem investigations and in vivo MRI studies (Figure 7). Although relatively coherent, some variations in the time courses are observed because the techniques are differently sensitive to mechanisms of WM organization and maturation. Let's keep in mind that MRI techniques remain indirect and macroscopic approaches to explore the developing microstructure. They can hardly investigate some mechanisms (e.g. fiber pruning), but their main advantage is to be non-invasive techniques that can be applied in vivo in healthy fetuses and infants. For instance, they are the only conceivable approach to investigate how brain maturation is influenced early on by environmental factors and nutrition (e.g. boosting of WM myelination by breastfeeding (Deoni, et al. 2013)).

Other emerging MRI techniques, such as magnetic susceptibility mapping and phase imaging, are promising to help characterize the microstructural properties of the developing white matter (Chen, et al. 2013; Lodygensky, et al. 2012; Zhong, et al. 2011). Of course, WM changes are not completed by 2 years of age, but are protracted in some brain regions until the end of adolescence; however it is beyond the scope of the current article to review all existing studies based on structural MRI (Giedd and Rapoport 2010; Paus 2005; Paus 2010; Paus, et al. 2001; Paus, et al. 1999) and DTI (Barnea-Goraly, et al. 2005; Eluvathingal, et al. 2007; Faria, et al. 2010; Lebel and Beaulieu 2011; Lebel, et al. 2008). Finally, the interactions between the developing white matter connectivity and the development of cortical regions will probably take a place of honour soon, since an increasing number of studies have recently provided early quantitative markers of cortical maturation (Leroy, et al. 2011a), that may also correlate with the development of infant cognitive abilities (Aeby, et al. 2013; Travis, et al. 2013).

To sum, correlation approaches based on complementary imaging approaches (including anatomical and functional imaging and behavioural assessments) enable to explore the developing brain at several levels, from brain structure development to the infant motor and cognitive acquisitions. Beyond normal development, these studies are crucial to understand the mechanisms of pathologies that result from early cerebral anomalies (e.g. genetic diseases, epilepsies, mental retardation, learning disorders), to assess the influence of early disturbances related to fetal conditions (e.g. intra-uterine growth restriction, teratogen exposures) or perinatal events (e.g. premature birth, neonatal stroke), and to follow the efficiency and robustness of medical interventions.

\section{Acknowledgements}

The author research are supported by the Fyssen Foundation, the McDonnell Foundation, the "Ecole des Neurosciences de Paris", the "Fondation Motrice", the "Fondation de France", the French National Agency for Research (ANR), the CIBM imaging center from Geneva and Lausanne, the Swiss National Science Foundation, the Leenards Foundation and the European consortium NEOBRAIN. 


\section{Figure 1: Anatomical images of the developing brain}

$\mathrm{T} 1 \mathrm{w}$ and $\mathrm{T} 2 \mathrm{w}$ images are presented for subjects of different ages: a preterm newborn of $31 \mathrm{w}$ of gestational age (GA), term-born infants at a post-term age (PTA) of $6 \mathrm{w}, 19 \mathrm{w}$ and 34w (PTA: post-natal age corrected for gestational age at birth, considering a term age of $40 \mathrm{w}$ ), and a young adult. Note the contrast inversion between grey and white matter during the first post-natal year. For the infants and adults, quantitative maps of $\mathrm{T} 1$ and $\mathrm{T} 2$ relaxation times (in seconds), and of myelin water fraction (MWF) are also presented. Within the white matter, T1 and T2 decrease with age, while MWF increases. Preterm images were acquired on a $1.5 \mathrm{~T}$ MRI system, the other images on a 3T system.

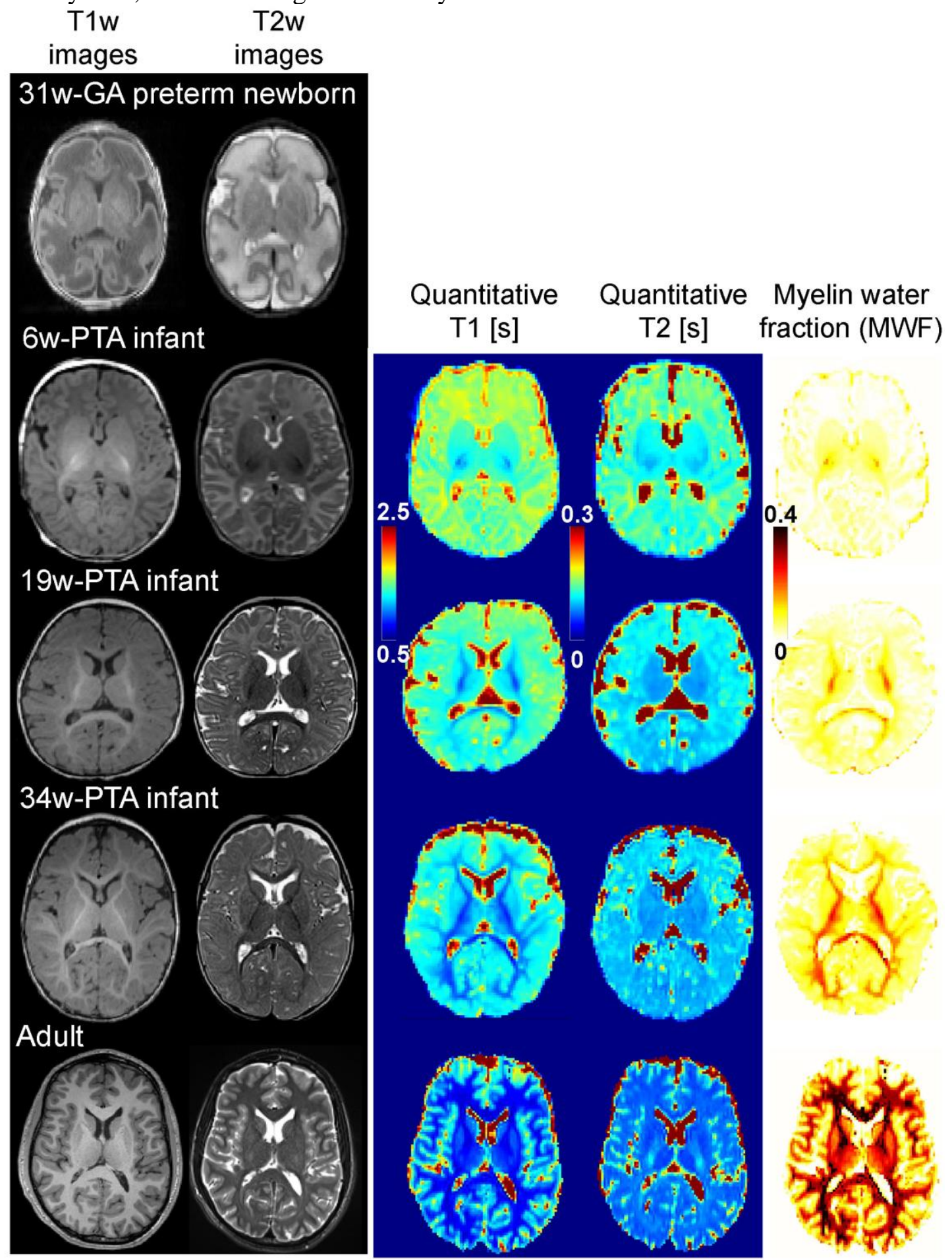




\section{Figure 2: DTI images of the developing brain}

DTI maps are presented for the same subjects as in Figure 1. Colour-coded directionality maps (FA-RGB, where colour informs on the direction of the tensor main eigenvector) nicely highlight early white matter organization, and immature bundles already demonstrate high fractional anisotropy (FA). The different DTI parameters provide different contrasts between brain tissues. Within the white matter, FA increases with age, while mean (MD), longitudinal $\left(\lambda_{/ /}\right)$and transverse $(\lambda \perp)$ diffusivities (in $10^{-3} \mathrm{~mm}^{2} \cdot \mathrm{s}^{-1}$ ) decrease.
Directionality Fractional
Mean
Longitudinal
Transverse
FA-RGB anisotropy FA diffusivity MD
diffusivity $\lambda$ diffusivity $\lambda_{\perp}$

\section{1w-GA preterm newborn}
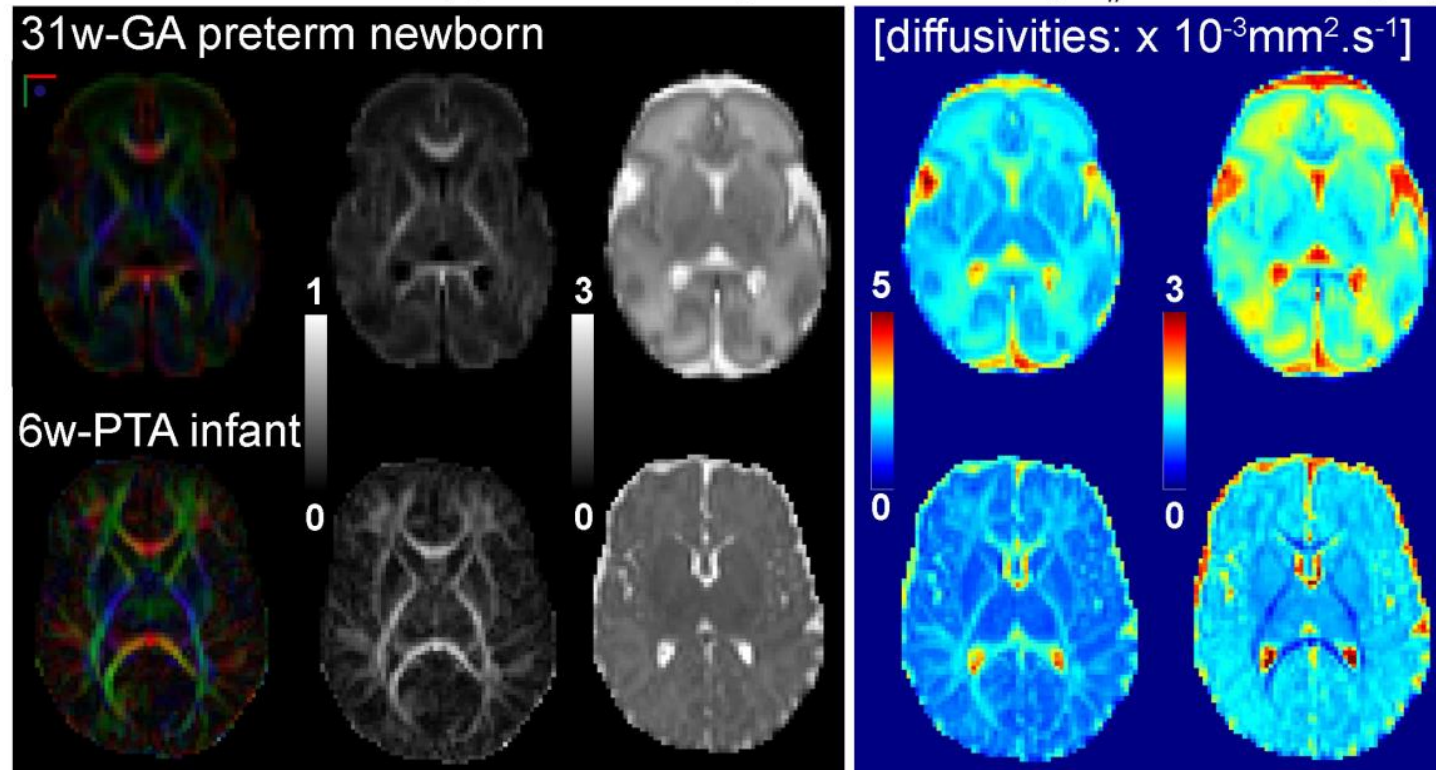

\section{9w-PTA infant}
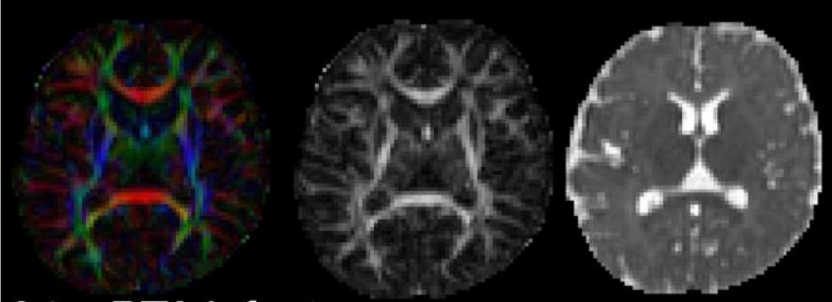

\section{4w-PTA infant}
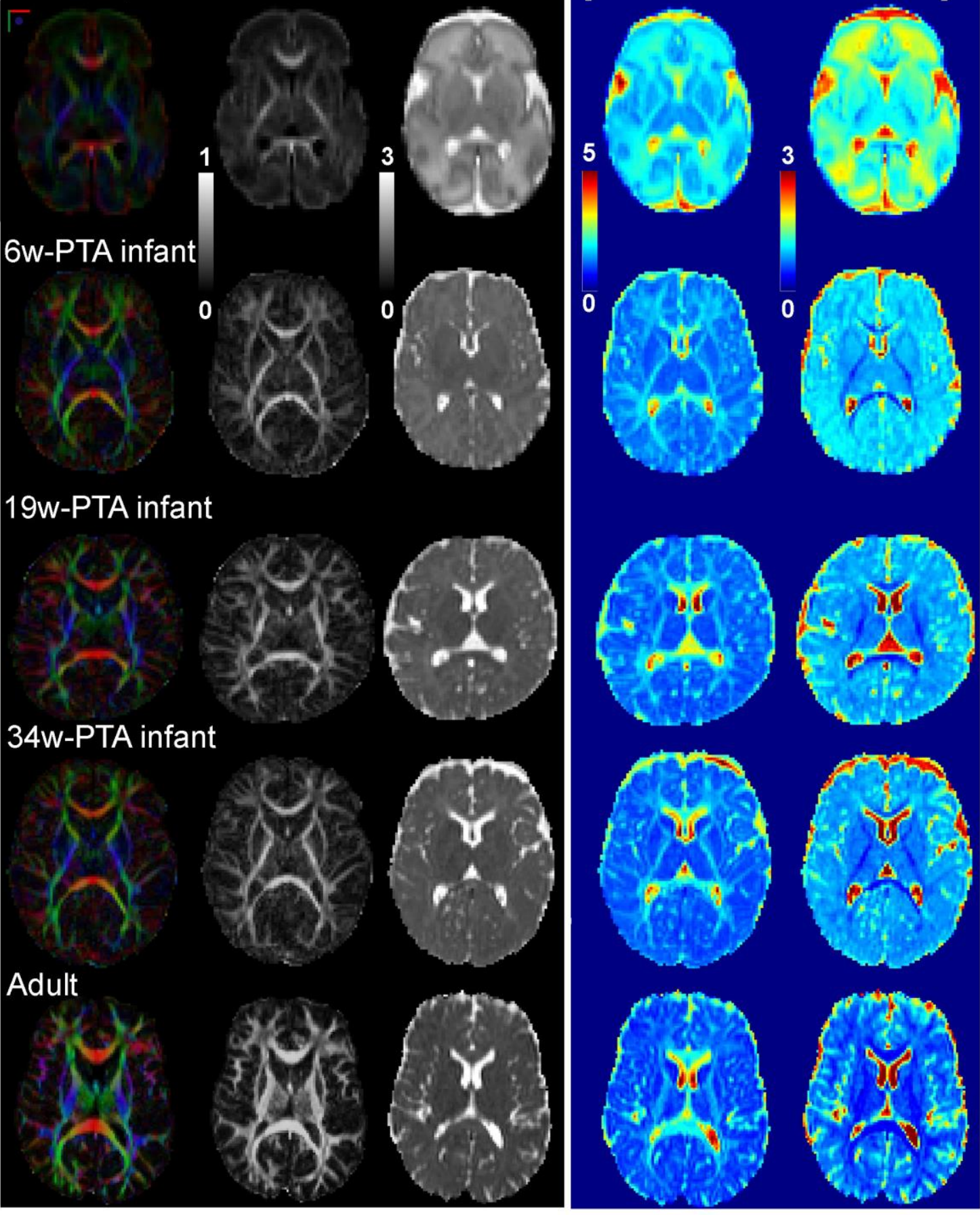


\section{Figure 3: Tractography of the developing white matter bundles}

Examples of major white matter bundles, reconstructed with regularized tractography using Connectomist software (Duclap, et al. 2012), are presented for the 6w-old infant and the adult of Figures 1 and 2: projection and limbic pathways (left column), and associative pathways (right column). Note the similar organization between the infant and adult brains.

Abbreviations: AF arcuate fasciculus; ALIC anterior limb of the internal capsule; CG cingulum; CST cortico-spinal tract; FOF fronto-occipital fasciculus; ILF inferior longitudinal fasciculus; OR optic radiations; SLF superior longitudinal fasciculus; STT spino-thalamic tract; UF uncinate fasciculus.

Projection and limbic pathways
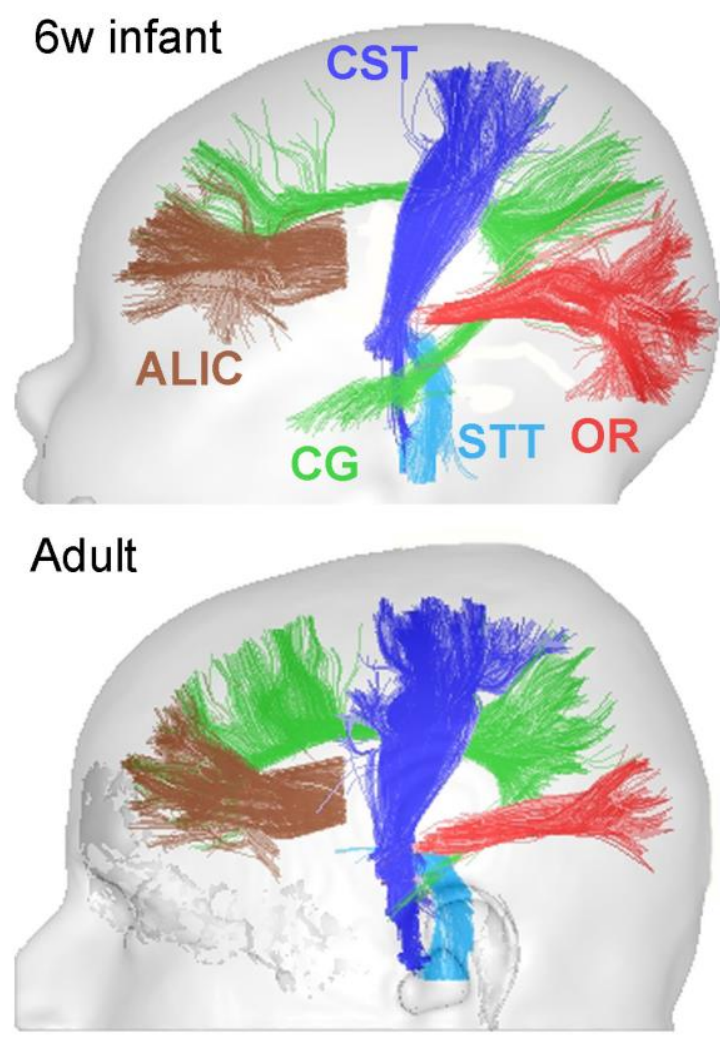

Association pathways
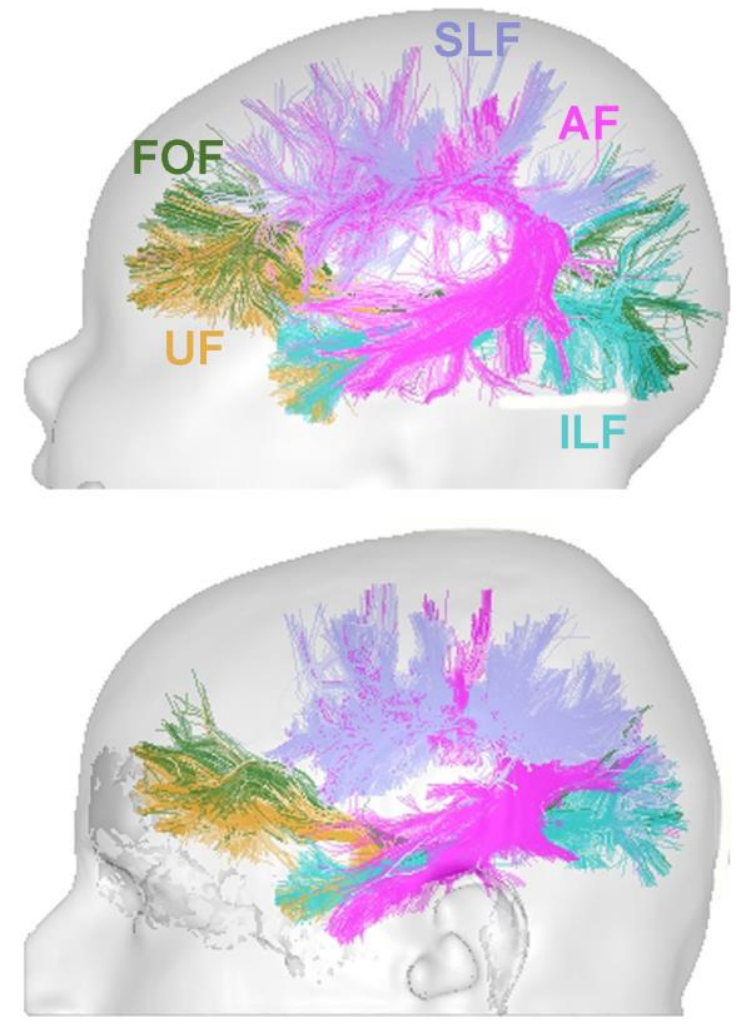


\section{Figure 4: Illustrations of maturation-related changes in MRI parameters}

a: The decreases in $\mathrm{T} 1$ and $\mathrm{T} 2$ relaxation times (increases in relaxation rates $\mathrm{R} 1=1 / \mathrm{T} 1$ and $\mathrm{R} 2=1 / \mathrm{T} 2$ ) are more intense in the developing white matter than in the developing grey matter, which leads to contrast inversions on $\mathrm{T} 1 \mathrm{w}$ and $\mathrm{T} 2 \mathrm{w}$ images during the first post-natal year (Figure 1). Post-mortem images of white matter myelin staining were reproduced from (Flechsig 1920).

b: During the myelination of white matter fibers, two successive processes occur: "premyelination" with oligodendrocytes and membranes proliferation, and "true" myelination. Both lead to changes in DTI parameters: e.g. increase in fractional anisotropy (FA) and decrease in transverse diffusivity $(\lambda \perp)$ in the case of a single maturing bundle (upper row) (Dubois, et al. 2008b). But changes are more complex in other configurations, for instance when crossing bundles are maturing at different times (lower row).

c: In summary, quantitative parameters are expected to change at different times depending on the major steps of WM maturation (bundles fasciculation, "pre-myelination", "true" myelination), suggesting strong parameters complementarity. In a single-bundle configuration, anisotropy (FA) increases, mean (MD) and transverse $(\lambda \perp)$ diffusivities decrease, while longitudinal diffusivity first increases (dashed line) then decreases (Dubois, et al. 2008b). T1 and T2 relaxation times decrease, whereas myelin water fraction (MWF) and magnetization transfer ratio (MTR) increase (the dashed line corresponds to MTR observations in preterm corpus callosum (Nossin-Manor, et al. 2012)).

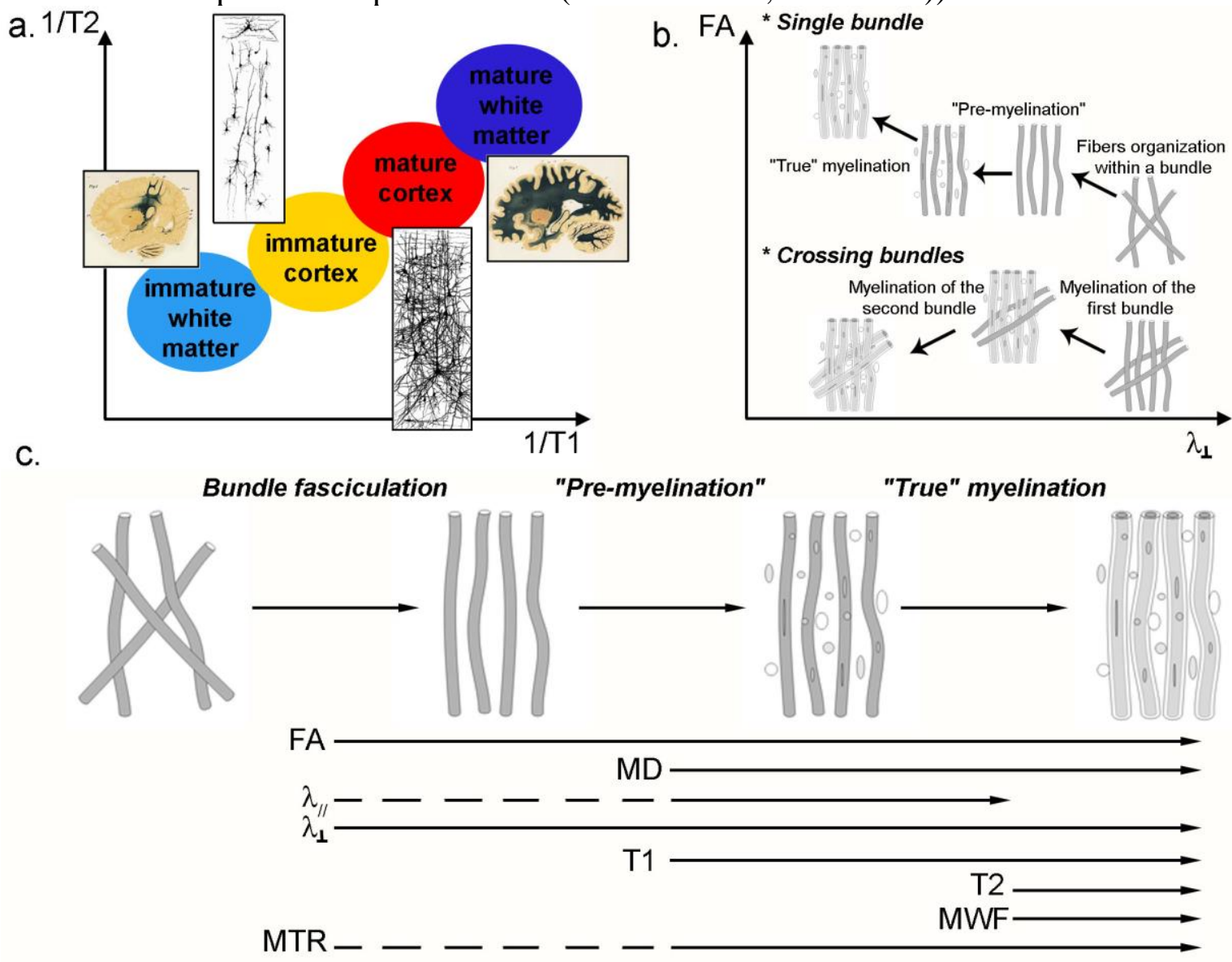




\section{Figure 5: Age-related changes in white matter volume and DTI parameters}

Age-related changes in WM volume (a) and in DTI parameters (b) are highlighted in different populations: preterm newborns (left column), at term-born newborns or infants (middle column) and during the first two post-natal years (right column). Note that WM volume increases more slowly than GM volume. Fractional anisotropy (FA) increases in major WM bundles, while mean (MD) and transverse $(\lambda \perp)$ diffusivities decrease. DTI parameters strongly differ among white matter bundles.

Figures were adapted with permission from different studies: WM volumes in preterm newborns imaged at 3T (Kuklisova-Murgasova, et al. 2011), in newborns at term imaged at 3T (Gilmore, et al. 2007), in infants at 0,1y and 2y of age imaged at 3T (Knickmeyer, et al. 2008); DTI parameters in preterm newborns imaged at 1.5T (Partridge, et al. 2004), in infants imaged at 1.5T (Dubois, et al. 2008b), in infants at 0, 1y and 2y of age imaged at 3T (Geng, et al. 2012).

Abbreviations: AFinf inferior branch of the arcuate fasciculus; ALIC anterior limb of the internal capsule; CG cingulum; CS centrum semiovale; CST cortico-spinal tract; EC external capsule; ILF inferior longitudinal fasciculus; OR optic radiations; PLIC posterior limb of the internal capsule; STT spino-thalamic tract; UF uncinate fasciculus.

a. WM volume
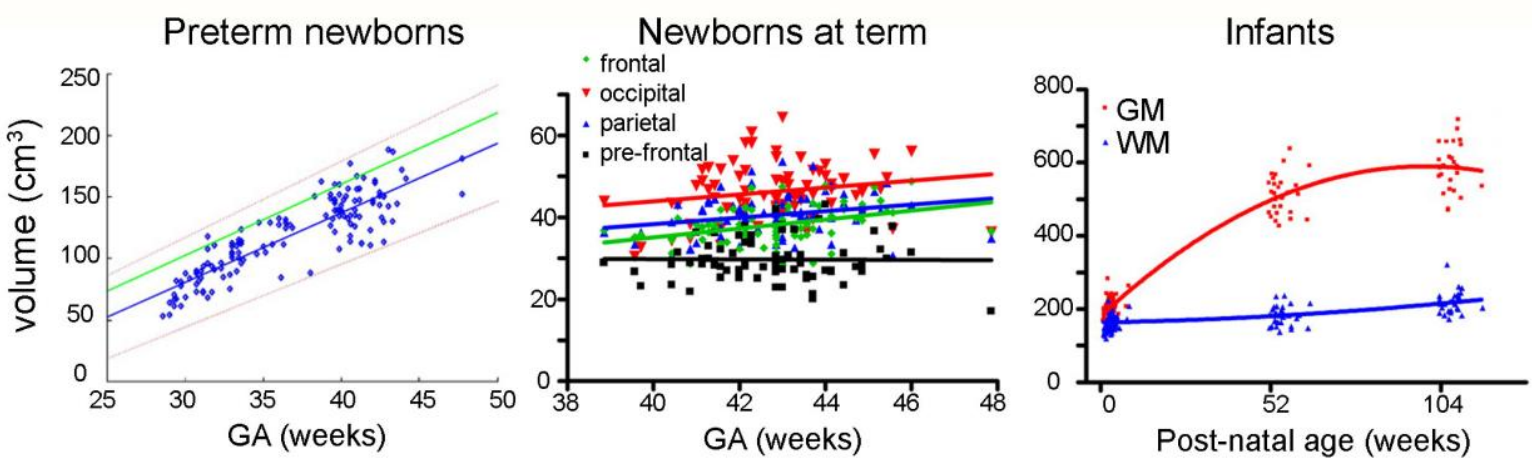

b. DTI parameters: fractional anisotropy and diffusivities
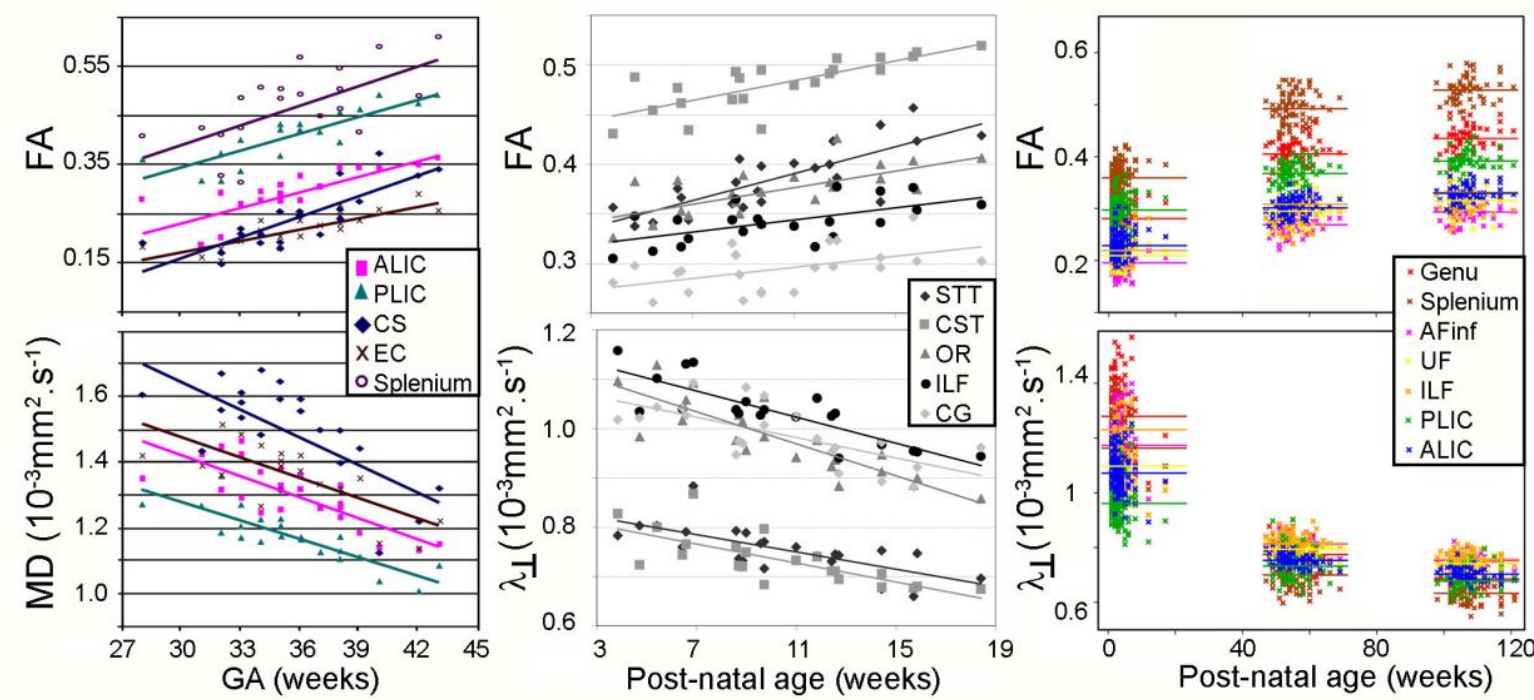


\section{Figure 6: Age-related changes in quantitative parameters related to myelin}

Relaxation times T1 and T2 (a), magnetization transfer ratio (MTR) (b) and myelin water fraction (MWF) (c) are shown during infancy and toddlerhood. T1 and T2 decrease exponentially with age while relaxation rates $(\mathrm{Ri}=1 / \mathrm{Ti})$, MTR and MWF increase (left column). Note parameters variability across WM regions, which demonstrate different temporal maturation courses (left and middle columns). Some correlations between the parameters have been shown (right and middle columns), but these correlations mainly rely on co-variations with the infants age.

Figures were adapted with permission from different studies: age-related changes in T2 and MTR at $1.5 \mathrm{~T}$ in infants (Engelbrecht, et al. 1998), variability in relaxation rates at 3T in newborns at term (Williams, et al. 2005), correlations between MTR, T1 and FA at 1.5T in preterm newborns (Nossin-Manor, et al. 2012), MWF increase at 3T in infants (Deoni, et al. 2012a).

Abbreviations: PLIC posterior limb of the internal capsule; PVWM peri-ventricular white matter.

\section{a. Relaxometries}
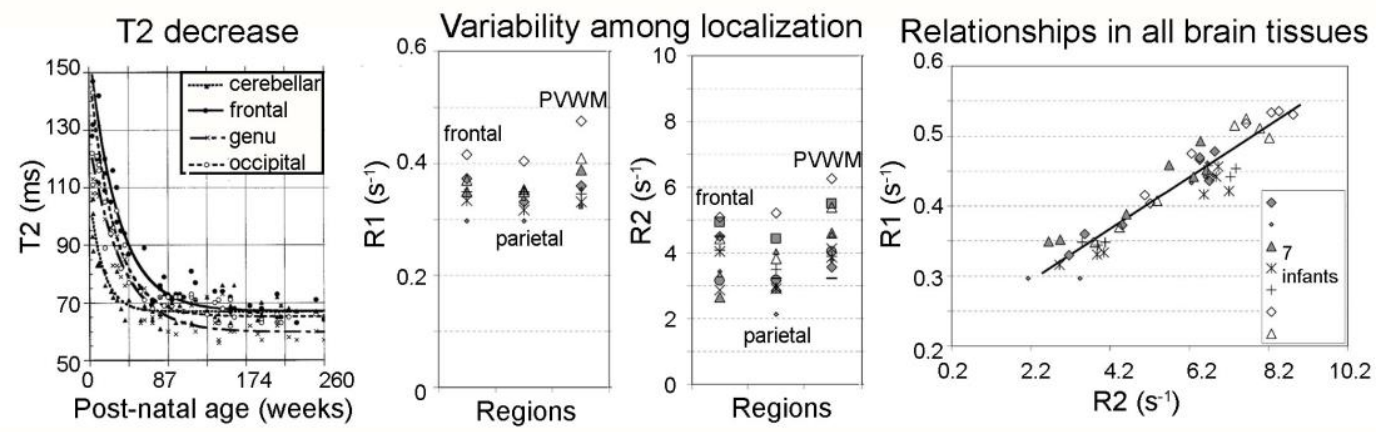

b. Magnetization transfer ratio (MTR)
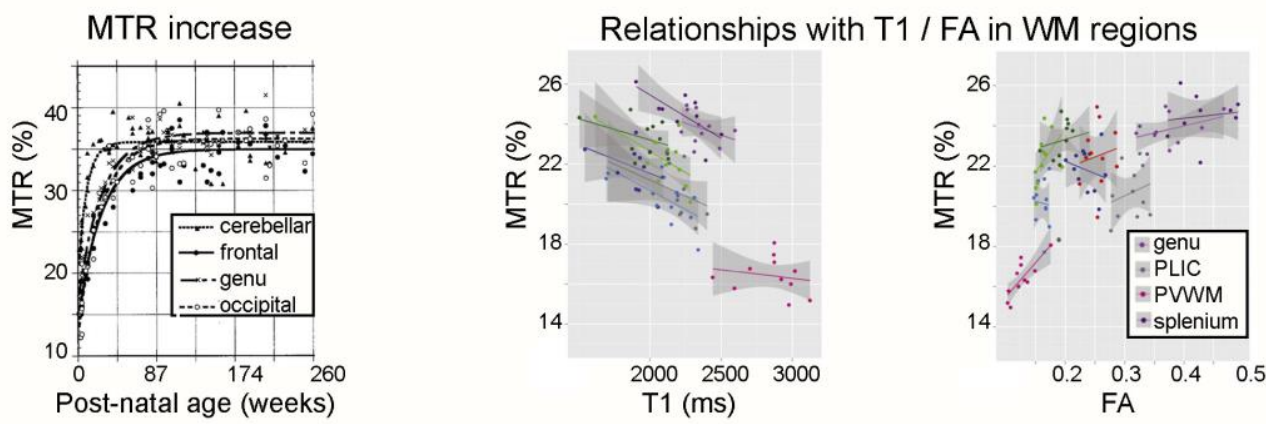

c. Myelin water fraction (MWF)
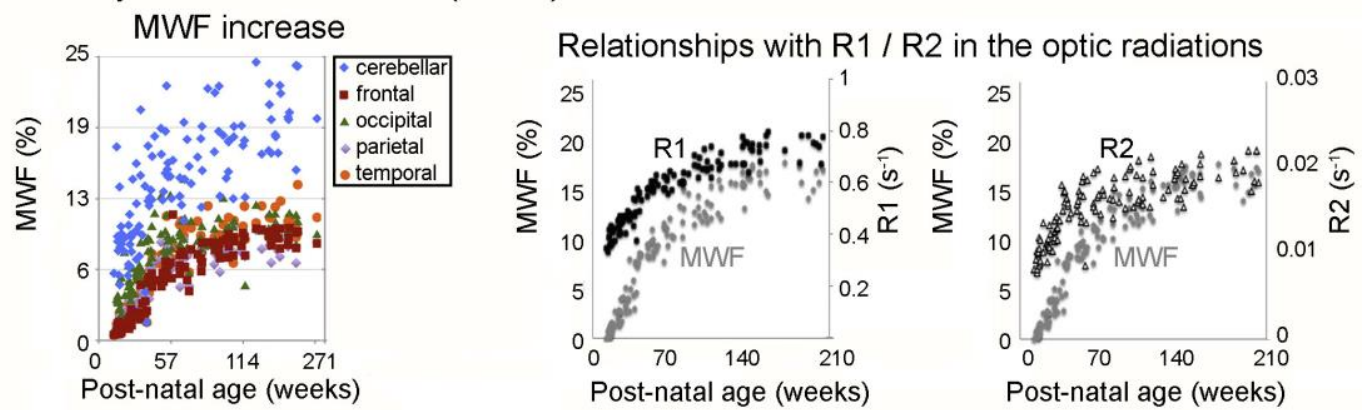


\section{Figure 7: General time-line of white matter development}

The time-courses of developmental mechanisms are tentatively summarised across WM bundles, according to post-mortem investigations and MRI studies. These mechanisms include the growth, pruning and myelination of axonal fibers, during the pre-term and postterm periods (fetal and post-natal ages in weeks). For each mechanism, approximate time periods are indicated. To our knowledge, information on the beginning and ending of axonal pruning are missing in the human brain. Purple-bordered arrows refer to the myelination process.

Abbreviations: AF arcuate fasciculus; ALIC anterior limb of the internal capsule; CC corpus callosum; CG cingulum; CR corona radiate; CST cortico-spinal tract; EC external capsule; FOF fronto-occipital fasciculus; ILF inferior longitudinal fasciculus; PLIC posterior limb of the internal capsule; OR optic radiations; SLF superior longitudinal fasciculus; STT spinothalamic tract; UF uncinate fasciculus.

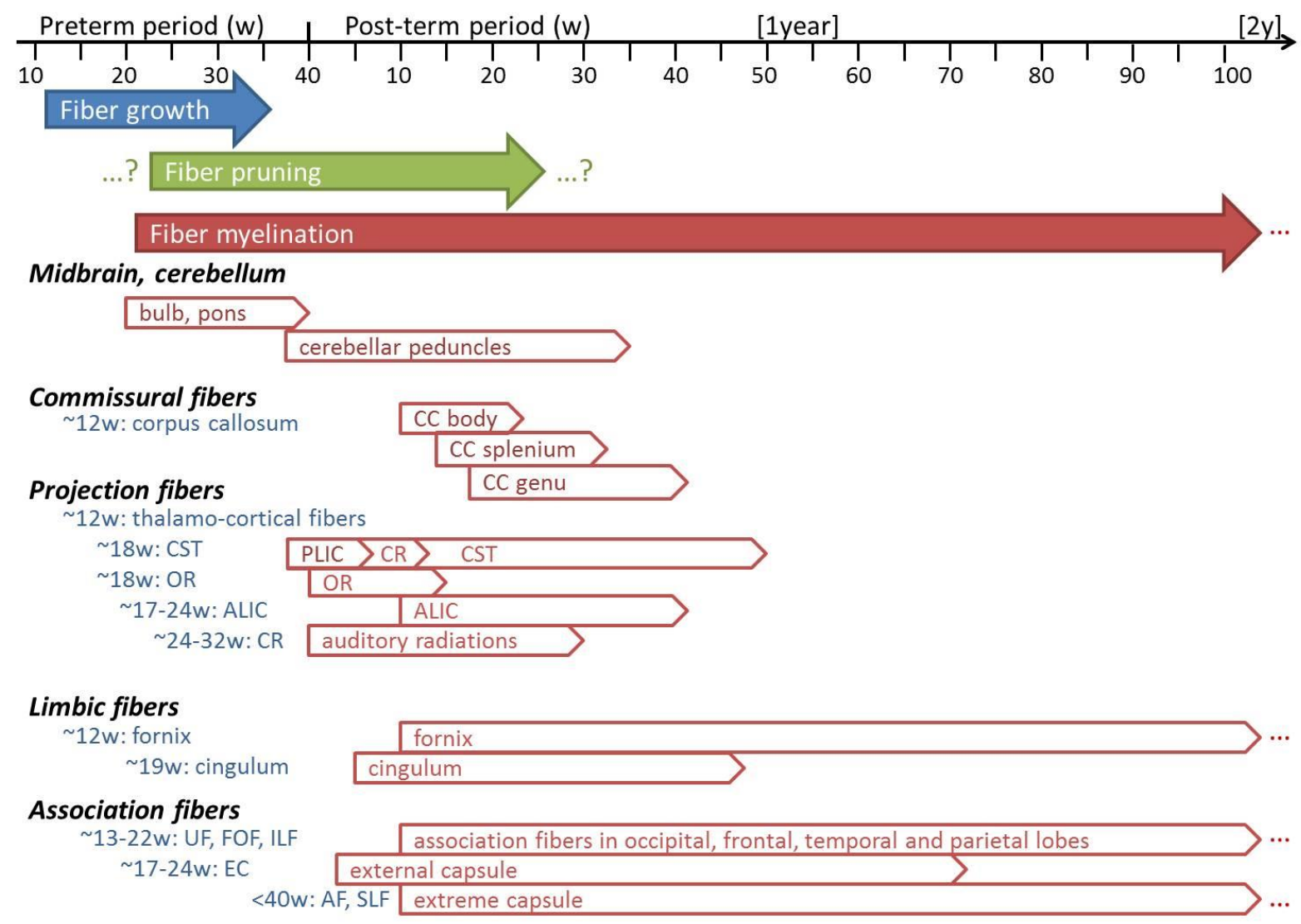




\section{References}

Aeby A, De Tiege X, Creuzil M, David P, Baleriaux D, Van Overmeire B, Metens T, Van Bogaert P. 2013. Language development at 2years is correlated to brain microstructure in the left superior temporal gyrus at term equivalent age: A diffusion tensor imaging study. Neuroimage 78C:145-151.

Aeby A, Liu Y, De Tiege X, Denolin V, David P, Baleriaux D, Kavec M, Metens T, Van Bogaert P. 2009. Maturation of thalamic radiations between 34 and 41 weeks' gestation: a combined voxel-based study and probabilistic tractography with diffusion tensor imaging. AJNR Am J Neuroradiol 30(9):1780-6.

Aeby A, Van Bogaert P, David P, Baleriaux D, Vermeylen D, Metens T, De Tiege X. 2012. Nonlinear microstructural changes in the right superior temporal sulcus and lateral occipitotemporal gyrus between 35 and 43weeks in the preterm brain. Neuroimage.

Anjari M, Srinivasan L, Allsop JM, Hajnal JV, Rutherford MA, Edwards AD, Counsell SJ. 2007. Diffusion tensor imaging with tract-based spatial statistics reveals local white matter abnormalities in preterm infants. Neuroimage 35(3):1021-7.

Ball G, Boardman JP, Aljabar P, Pandit A, Arichi T, Merchant N, Rueckert D, Edwards AD, Counsell SJ. 2012a. The influence of preterm birth on the developing thalamocortical connectome. Cortex.

Ball G, Boardman JP, Rueckert D, Aljabar P, Arichi T, Merchant N, Gousias IS, Edwards AD, Counsell SJ. 2012b. The effect of preterm birth on thalamic and cortical development. Cereb Cortex 22(5):1016-24.

Ball G, Srinivasan L, Aljabar P, Counsell SJ, Durighel G, Hajnal JV, Rutherford MA, Edwards AD. 2013. Development of cortical microstructure in the preterm human brain. Proc Natl Acad Sci U S A.

Baratti C, Barnett AS, Pierpaoli C. 1999. Comparative MR imaging study of brain maturation in kittens with T1, T2, and the trace of the diffusion tensor. Radiology 210(1):133-42.

Barkovich AJ. 2000. Concepts of myelin and myelination in neuroradiology. AJNR Am J Neuroradiol 21(6):1099-109.

Barkovich AJ, Kjos BO, Jackson DE, Jr., Norman D. 1988. Normal maturation of the neonatal and infant brain: MR imaging at $1.5 \mathrm{~T}$. Radiology 166(1 Pt 1):173-80.

Barkovich AJ, Lyon G, Evrard P. 1992. Formation, maturation, and disorders of white matter. AJNR Am J Neuroradiol 13(2):447-61.

Barnea-Goraly N, Menon V, Eckert M, Tamm L, Bammer R, Karchemskiy A, Dant CC, Reiss AL. 2005. White matter development during childhood and adolescence: a crosssectional diffusion tensor imaging study. Cereb Cortex 15(12):1848-54.

Barres BA, Raff MC. 1993. Proliferation of oligodendrocyte precursor cells depends on electrical activity in axons. Nature 361(6409):258-60.

Bassi L, Ricci D, Volzone A, Allsop JM, Srinivasan L, Pai A, Ribes C, Ramenghi LA, Mercuri E, Mosca F and others. 2008. Probabilistic diffusion tractography of the optic radiations and visual function in preterm infants at term equivalent age. Brain $131(\mathrm{Pt}$ 2):573-82.

Baumann N, Pham-Dinh D. 2001. Biology of oligodendrocyte and myelin in the mammalian central nervous system. Physiol Rev 81(2):871-927.

Beaulieu C. 2002. The basis of anisotropic water diffusion in the nervous system - a technical review. NMR Biomed 15(7-8):435-55.

Beaulieu C, Fenrich FR, Allen PS. 1998. Multicomponent water proton transverse relaxation and T2-discriminated water diffusion in myelinated and nonmyelinated nerve. Magn Reson Imaging 16(10):1201-10. 
Berman JI, Glass HC, Miller SP, Mukherjee P, Ferriero DM, Barkovich AJ, Vigneron DB, Henry RG. 2009. Quantitative fiber tracking analysis of the optic radiation correlated with visual performance in premature newborns. AJNR Am J Neuroradiol 30(1):1204.

Berman JI, Mukherjee P, Partridge SC, Miller SP, Ferriero DM, Barkovich AJ, Vigneron DB, Henry RG. 2005. Quantitative diffusion tensor MRI fiber tractography of sensorimotor white matter development in premature infants. Neuroimage 27(4):862-71.

Brauer J, Anwander A, Perani D, Friederici AD. 2013. Dorsal and ventral pathways in language development. Brain Lang.

Brody BA, Kinney HC, Kloman AS, Gilles FH. 1987. Sequence of central nervous system myelination in human infancy. I. An autopsy study of myelination. J Neuropathol Exp Neurol 46(3):283-301.

Buchel C, Raedler T, Sommer M, Sach M, Weiller C, Koch MA. 2004. White matter asymmetry in the human brain: a diffusion tensor MRI study. Cereb Cortex 14(9):94551.

Bui T, Daire JL, Chalard F, Zaccaria I, Alberti C, Elmaleh M, Garel C, Luton D, Blanc N, Sebag G. 2006. Microstructural development of human brain assessed in utero by diffusion tensor imaging. Pediatr Radiol 36(11):1133-40.

Butt AM, Berry M. 2000. Oligodendrocytes and the control of myelination in vivo: new insights from the rat anterior medullary velum. J Neurosci Res 59(4):477-88.

Chen WC, Foxley S, Miller KL. 2013. Detecting microstructural properties of white matter based on compartmentalization of magnetic susceptibility. Neuroimage.

Chen Y, An H, Zhu H, Jewells V, Armao D, Shen D, Gilmore JH, Lin W. 2011. Longitudinal regression analysis of spatial-temporal growth patterns of geometrical diffusion measures in early postnatal brain development with diffusion tensor imaging. Neuroimage 58(4):993-1005.

Chi JG, Dooling EC, Gilles FH. 1977b. Left-right asymmetries of the temporal speech areas of the human fetus. Arch Neurol 34(6):346-8.

Choe MS, Ortiz-Mantilla S, Makris N, Gregas M, Bacic J, Haehn D, Kennedy D, Pienaar R, Caviness VS, Jr., Benasich AA and others. 2012. Regional Infant Brain Development: An MRI-Based Morphometric Analysis in 3 to 13 Month Olds. Cereb Cortex.

Colby JB, Soderberg L, Lebel C, Dinov ID, Thompson PM, Sowell ER. 2012. Along-tract statistics allow for enhanced tractography analysis. Neuroimage 59(4):3227-42.

Counsell SJ, Edwards AD, Chew AT, Anjari M, Dyet LE, Srinivasan L, Boardman JP, Allsop JM, Hajnal JV, Rutherford MA and others. 2008. Specific relations between neurodevelopmental abilities and white matter microstructure in children born preterm. Brain 131(Pt 12):3201-8.

Counsell SJ, Maalouf EF, Fletcher AM, Duggan P, Battin M, Lewis HJ, Herlihy AH, Edwards AD, Bydder GM, Rutherford MA. 2002. MR imaging assessment of myelination in the very preterm brain. AJNR Am J Neuroradiol 23(5):872-81.

Dean DC, 3rd, O'Muircheartaigh J, Dirks H, Waskiewicz N, Lehman K, Walker L, Han M, Deoni SC. 2013. Modeling healthy male white matter and myelin development: 3 through 60months of age. Neuroimage.

deAzevedo LC, Hedin-Pereira C, Lent R. 1997. Callosal neurons in the cingulate cortical plate and subplate of human fetuses. J Comp Neurol 386(1):60-70.

Dehaene-Lambertz G, Dehaene S, Hertz-Pannier L. 2002. Functional neuroimaging of speech perception in infants. Science 298(5600):2013-5.

Dehaene-Lambertz G, Hertz-Pannier L, Dubois J. 2006. Nature and nurture in language acquisition: anatomical and functional brain-imaging studies in infants. Trends Neurosci 29(7):367-73. 
Demerens C, Stankoff B, Logak M, Anglade P, Allinquant B, Couraud F, Zalc B, Lubetzki C. 1996. Induction of myelination in the central nervous system by electrical activity. Proc Natl Acad Sci U S A 93(18):9887-92.

Deoni SC, Dean DC, 3rd, O'Muircheartaigh J, Dirks H, Jerskey BA. 2012a. Investigating white matter development in infancy and early childhood using myelin water faction and relaxation time mapping. Neuroimage 63(3):1038-53.

Deoni SC, Dean DC, 3rd, Piryatinksy I, O'Muircheartaigh J, Waskiewicz N, Lehman K, Han M, Dirks H. 2013. Breastfeeding and early white matter development: A crosssectional study. Neuroimage.

Deoni SC, Matthews L, Kolind SH. 2012b. One component? Two components? Three? The effect of including a nonexchanging "free" water component in multicomponent driven equilibrium single pulse observation of T1 and T2. Magn Reson Med 70(1):147-54.

Deoni SC, Mercure E, Blasi A, Gasston D, Thomson A, Johnson M, Williams SC, Murphy DG. 2011. Mapping infant brain myelination with magnetic resonance imaging. J Neurosci 31(2):784-91.

Douaud G, Jbabdi S, Behrens TE, Menke RA, Gass A, Monsch AU, Rao A, Whitcher B, Kindlmann G, Matthews PM and others. 2011. DTI measures in crossing-fibre areas: increased diffusion anisotropy reveals early white matter alteration in MCI and mild Alzheimer's disease. Neuroimage 55(3):880-90.

Draganova R, Eswaran H, Murphy P, Lowery C, Preissl H. 2007. Serial magnetoencephalographic study of fetal and newborn auditory discriminative evoked responses. Early Hum Dev 83(3):199-207.

Drobyshevsky A, Song SK, Gamkrelidze G, Wyrwicz AM, Derrick M, Meng F, Li L, Ji X, Trommer B, Beardsley DJ and others. 2005. Developmental changes in diffusion anisotropy coincide with immature oligodendrocyte progression and maturation of compound action potential. J Neurosci 25(25):5988-97.

Dubois J, Benders M, Cachia A, Lazeyras F, Ha-Vinh Leuchter R, Sizonenko SV, BorradoriTolsa C, Mangin JF, Huppi PS. 2008a. Mapping the early cortical folding process in the preterm newborn brain. Cereb Cortex 18(6):1444-54.

Dubois J, Benders M, Lazeyras F, Borradori-Tolsa C, Leuchter RH, Mangin JF, Huppi PS. 2010a. Structural asymmetries of perisylvian regions in the preterm newborn. Neuroimage 52(1):32-42.

Dubois J, Dehaene-Lambertz G, Perrin M, Mangin JF, Cointepas Y, Duchesnay E, Le Bihan D, Hertz-Pannier L. 2008b. Asynchrony of the early maturation of white matter bundles in healthy infants: quantitative landmarks revealed noninvasively by diffusion tensor imaging. Hum Brain Mapp 29(1):14-27.

Dubois J, Dehaene-Lambertz G, Soares C, Cointepas Y, Le Bihan D, Hertz-Pannier L. 2008c. Microstructural correlates of infant functional development: example of the visual pathways. J Neurosci 28(8):1943-8.

Dubois J, Hertz-Pannier L, Cachia A, Mangin JF, Le Bihan D, Dehaene-Lambertz G. 2009. Structural asymmetries in the infant language and sensori-motor networks. Cereb Cortex 19(2):414-23.

Dubois J, Hertz-Pannier L, Dehaene-Lambertz G, Cointepas Y, Le Bihan D. 2006a. Assessment of the early organization and maturation of infants' cerebral white matter fiber bundles: a feasibility study using quantitative diffusion tensor imaging and tractography. Neuroimage 30(4):1121-32.

Dubois J, Kulikova S, Hertz-Pannier L, Mangin JF, Dehaene-Lambertz G, Poupon C. in revision. Correction strategy for diffusion-weighted images corrupted with motion: 
Application to the DTI evaluation of infants' white matter. Magnetic Resonance Imaging.

Dubois J, Poupon C, Lethimonnier F, Le Bihan D. 2006b. Optimized diffusion gradient orientation schemes for corrupted clinical DTI data sets. MAGMA 19(3):134-43.

Dubois J, Poupon C, Thirion B, Leroy F, Simonnet H, Hertz-Pannier L, Dehaene-Lambertz G. in preparation. Exploring the language networks in the human infant brain.

Duclap D, Schmitt B, Lebois A, Riff O, Guevara P, Marrakchi-Kacem L, Brion V, Poupon F, Mangin JF, Poupon C. 2012. Connectomist-2.0: a novel diffusion analysis toolbox for BrainVISA. Proceedings of the 29th ESMRMB meeting:842.

Dudink J, Lequin M, van Pul C, Buijs J, Conneman N, van Goudoever J, Govaert P. 2007. Fractional anisotropy in white matter tracts of very-low-birth-weight infants. Pediatr Radiol 37(12):1216-23.

Eluvathingal TJ, Hasan KM, Kramer L, Fletcher JM, Ewing-Cobbs L. 2007. Quantitative diffusion tensor tractography of association and projection fibers in normally developing children and adolescents. Cereb Cortex 17(12):2760-8.

Engelbrecht V, Rassek M, Preiss S, Wald C, Modder U. 1998. Age-dependent changes in magnetization transfer contrast of white matter in the pediatric brain. AJNR Am J Neuroradiol 19(10):1923-9.

Erberich SG, Panigrahy A, Friedlich P, Seri I, Nelson MD, Gilles F. 2006. Somatosensory lateralization in the newborn brain. Neuroimage 29(1):155-61.

Fan Y, Shi F, Smith JK, Lin W, Gilmore JH, Shen D. 2011. Brain anatomical networks in early human brain development. Neuroimage 54(3):1862-71.

Faria AV, Zhang J, Oishi K, Li X, Jiang H, Akhter K, Hermoye L, Lee SK, Hoon A, Stashinko E and others. 2010. Atlas-based analysis of neurodevelopment from infancy to adulthood using diffusion tensor imaging and applications for automated abnormality detection. Neuroimage 52(2):415-28.

Feess-Higgins A, Laroche JC. 1987. Development of the human foetal brain: an anatomical atlas. Inserm-CNRS, Masson.

Flechsig P. 1920. Anatomie des Menschlichen Gehirn und Rückenmarks, auf myelogenetischer grundlage $\mathrm{G}$. Thieme.

Forbes KP, Pipe JG, Bird CR. 2002. Changes in brain water diffusion during the 1st year of life. Radiology 222(2):405-9.

Friede RL. 1972. Control of myelin formation by axon caliber (with a model of the control mechanism). J Comp Neurol 144(2):233-52.

Gao W, Lin W, Chen Y, Gerig G, Smith JK, Jewells V, Gilmore JH. 2009. Temporal and spatial development of axonal maturation and myelination of white matter in the developing brain. AJNR Am J Neuroradiol 30(2):290-6.

Geng X, Gouttard S, Sharma A, Gu H, Styner M, Lin W, Gerig G, Gilmore JH. 2012. Quantitative tract-based white matter development from birth to age 2years. Neuroimage 61(3):542-57.

Giedd JN, Rapoport JL. 2010. Structural MRI of pediatric brain development: what have we learned and where are we going? Neuron 67(5):728-34.

Gilles F, Shankle W, Dooling E. 1983. Myelinated tracts: growth patterns. Gilles F., Leviton A. and Dooling E. eds. John Wright PSG, Boston.

Gilmore JH, Lin W, Prastawa MW, Looney CB, Vetsa YS, Knickmeyer RC, Evans DD, Smith JK, Hamer RM, Lieberman JA and others. 2007. Regional gray matter growth, sexual dimorphism, and cerebral asymmetry in the neonatal brain. J Neurosci 27(6):1255-60. 
Groeschel S, Vollmer B, King MD, Connelly A. 2010. Developmental changes in cerebral grey and white matter volume from infancy to adulthood. Int $\mathbf{J}$ Dev Neurosci 28(6):481-9.

Groppo M, Ricci D, Bassi L, Merchant N, Doria V, Arichi T, Allsop JM, Ramenghi L, Fox MJ, Cowan FM and others. 2012. Development of the optic radiations and visual function after premature birth. Cortex.

Guevara P, Duclap D, Poupon C, Marrakchi-Kacem L, Fillard P, Le Bihan D, Leboyer M, Houenou J, Mangin JF. 2012. Automatic fiber bundle segmentation in massive tractography datasets using a multi-subject bundle atlas. Neuroimage 61(4):1083-99.

Guevara P, Poupon C, Riviere D, Cointepas Y, Descoteaux M, Thirion B, Mangin JF. 2011. Robust clustering of massive tractography datasets. Neuroimage 54(3):1975-93.

Guillery RW. 2005. Is postnatal neocortical maturation hierarchical? Trends Neurosci 28(10):512-7.

Gyllensten L, Malmfors T. 1963. Myelinization of the optic nerve and its dependence on visual function--a quantitative investigation in mice. J Embryol Exp Morphol 11:25566.

Hagmann P, Sporns O, Madan N, Cammoun L, Pienaar R, Wedeen VJ, Meuli R, Thiran JP, Grant PE. 2010. White matter maturation reshapes structural connectivity in the late developing human brain. Proc Natl Acad Sci U S A 107(44):19067-72.

Hardy RJ, Friedrich VL, Jr. 1996. Progressive remodeling of the oligodendrocyte process arbor during myelinogenesis. Dev Neurosci 18(4):243-54.

Haselgrove J, Moore J, Wang Z, Traipe E, Bilaniuk L. 2000. A method for fast multislice T1 measurement: feasibility studies on phantoms, young children, and children with Canavan's disease. J Magn Reson Imaging 11(4):360-7.

Hermoye L, Saint-Martin C, Cosnard G, Lee SK, Kim J, Nassogne MC, Menten R, Clapuyt P, Donohue PK, Hua K and others. 2006. Pediatric diffusion tensor imaging: normal database and observation of the white matter maturation in early childhood. Neuroimage 29(2):493-504.

Huang H, Xue R, Zhang J, Ren T, Richards LJ, Yarowsky P, Miller MI, Mori S. 2009. Anatomical characterization of human fetal brain development with diffusion tensor magnetic resonance imaging. J Neurosci 29(13):4263-73.

Huang H, Zhang J, Wakana S, Zhang W, Ren T, Richards LJ, Yarowsky P, Donohue P, Graham E, van Zijl PC and others. 2006. White and gray matter development in human fetal, newborn and pediatric brains. Neuroimage 33(1):27-38.

Huppi PS, Dubois J. 2006. Diffusion tensor imaging of brain development. Semin Fetal Neonatal Med 11(6):489-97.

Huppi PS, Maier SE, Peled S, Zientara GP, Barnes PD, Jolesz FA, Volpe JJ. 1998a. Microstructural development of human newborn cerebral white matter assessed in vivo by diffusion tensor magnetic resonance imaging. Pediatr Res 44(4):584-90.

Huppi PS, Schuknecht B, Boesch C, Bossi E, Felblinger J, Fusch C, Herschkowitz N. 1996. Structural and neurobehavioral delay in postnatal brain development of preterm infants. Pediatr Res 39(5):895-901.

Huppi PS, Warfield S, Kikinis R, Barnes PD, Zientara GP, Jolesz FA, Tsuji MK, Volpe JJ. 1998b. Quantitative magnetic resonance imaging of brain development in premature and mature newborns. Ann Neurol 43(2):224-35.

Huttenlocher PR, Bonnier C. 1991. Effects of changes in the periphery on development of the corticospinal motor system in the rat. Brain Res Dev Brain Res 60(2):253-60.

Innocenti GM, Price DJ. 2005. Exuberance in the development of cortical networks. Nat Rev Neurosci 6(12):955-65. 
Ishibashi T, Dakin KA, Stevens B, Lee PR, Kozlov SV, Stewart CL, Fields RD. 2006. Astrocytes promote myelination in response to electrical impulses. Neuron 49(6):82332.

Jiang S, Xue H, Counsell S, Anjari M, Allsop J, Rutherford M, Rueckert D, Hajnal JV. 2009. Diffusion tensor imaging (DTI) of the brain in moving subjects: application to in-utero fetal and ex-utero studies. Magn Reson Med 62(3):645-55.

Judas M, Rados M, Jovanov-Milosevic N, Hrabac P, Stern-Padovan R, Kostovic I. 2005. Structural, immunocytochemical, and $\mathrm{mr}$ imaging properties of periventricular crossroads of growing cortical pathways in preterm infants. AJNR Am J Neuroradiol 26(10):2671-84.

Kanold PO, Luhmann HJ. 2010. The subplate and early cortical circuits. Annu Rev Neurosci 33:23-48.

Kasprian G, Brugger PC, Schopf V, Mitter C, Weber M, Hainfellner JA, Prayer D. 2013. Assessing prenatal white matter connectivity in commissural agenesis. Brain $136(\mathrm{Pt}$ 1):168-79.

Kasprian G, Brugger PC, Weber M, Krssak M, Krampl E, Herold C, Prayer D. 2008. In utero tractography of fetal white matter development. Neuroimage 43(2):213-24.

Kinney HC, Brody BA, Kloman AS, Gilles FH. 1988. Sequence of central nervous system myelination in human infancy. II. Patterns of myelination in autopsied infants. J Neuropathol Exp Neurol 47(3):217-34.

Knickmeyer RC, Gouttard S, Kang C, Evans D, Wilber K, Smith JK, Hamer RM, Lin W, Gerig G, Gilmore JH. 2008. A structural MRI study of human brain development from birth to 2 years. J Neurosci 28(47):12176-82.

Kolasinski J, Takahashi E, Stevens AA, Benner T, Fischl B, Zollei L, Grant PE. 2013. Radial and tangential neuronal migration pathways in the human fetal brain: Anatomically distinct patterns of diffusion MRI coherence. Neuroimage.

Kostovic I, Jovanov-Milosevic N. 2006. The development of cerebral connections during the first 20-45 weeks' gestation. Semin Fetal Neonatal Med 11(6):415-22.

Kostovic I, Judas M. 2010. The development of the subplate and thalamocortical connections in the human foetal brain. Acta Paediatr 99(8):1119-27.

Krishnan ML, Dyet LE, Boardman JP, Kapellou O, Allsop JM, Cowan F, Edwards AD, Rutherford MA, Counsell SJ. 2007. Relationship between white matter apparent diffusion coefficients in preterm infants at term-equivalent age and developmental outcome at 2 years. Pediatrics 120(3):e604-9.

Kucharczyk W, Macdonald PM, Stanisz GJ, Henkelman RM. 1994. Relaxivity and magnetization transfer of white matter lipids at MR imaging: importance of cerebrosides and $\mathrm{pH}$. Radiology 192(2):521-9.

Kuklisova-Murgasova M, Aljabar P, Srinivasan L, Counsell SJ, Doria V, Serag A, Gousias IS, Boardman JP, Rutherford MA, Edwards AD and others. 2011. A dynamic 4D probabilistic atlas of the developing brain. Neuroimage 54(4):2750-63.

Kulikova S, Hertz-Pannier L, Dehaene-Lambertz G, Poupon C, Dubois J. 2013a. Comparison of quantitative MRI parameters in the developing white matter bundles. Proceedings of the $30^{\text {th }}$ ESMRMB meeting: 660 .

Kulikova S, Hertz-Pannier L, Dehaene-Lambertz G, Poupon C, Dubois J. 2013b. Multiparametric Evaluation of the White Matter Maturation. Proceedings of the $30^{\text {th }}$ ESMRMB meeting:476.

Kulikova S, Hertz-Pannier L, Dehaene-Lambertz G, Poupon C, Dubois J. in preparation. Multi-parametric Evaluation of the White Matter Maturation.

LaMantia AS, Rakic P. 1990. Axon overproduction and elimination in the corpus callosum of the developing rhesus monkey. J Neurosci 10(7):2156-75. 
Lancaster JL, Andrews T, Hardies LJ, Dodd S, Fox PT. 2003. Three-pool model of white matter. J Magn Reson Imaging 17(1):1-10.

Langworthy OR. 1928. A correlated study of the development of reflex activity in fetal and young kittens and the myelinization of the tracts in the nervous system. Contrib Embryol 20:127-172.

Langworthy OR. 1928b. The behaviour of pouch young opossums correlated with the myelinization of tracts in the central nervous system. J Comp Neurol 46:201-248.

Le Bihan D. 2003. Looking into the functional architecture of the brain with diffusion MRI. Nat Rev Neurosci 4(6):469-80.

Le Bihan D, Johansen-Berg H. 2012. Diffusion MRI at 25: exploring brain tissue structure and function. Neuroimage 61(2):324-41.

Le Bihan D, Mangin JF, Poupon C, Clark CA, Pappata S, Molko N, Chabriat H. 2001. Diffusion tensor imaging: concepts and applications. J Magn Reson Imaging 13(4):534-46.

Lebel C, Beaulieu C. 2011. Longitudinal development of human brain wiring continues from childhood into adulthood. J Neurosci 31(30):10937-47.

Lebel C, Walker L, Leemans A, Phillips L, Beaulieu C. 2008. Microstructural maturation of the human brain from childhood to adulthood. Neuroimage 40(3):1044-55.

Leppert IR, Almli CR, McKinstry RC, Mulkern RV, Pierpaoli C, Rivkin MJ, Pike GB. 2009. $\mathrm{T}(2)$ relaxometry of normal pediatric brain development. J Magn Reson Imaging 29(2):258-67.

Leroy F, Glasel H, Dubois J, Hertz-Pannier L, Thirion B, Mangin JF, Dehaene-Lambertz G. 2011a. Early maturation of the linguistic dorsal pathway in human infants. J Neurosci 31(4):1500-6.

Leroy F, Mangin JF, Rousseau F, Glasel H, Hertz-Pannier L, Dubois J, Dehaene-Lambertz G. $2011 \mathrm{~b}$. Atlas-free surface reconstruction of the cortical grey-white interface in infants. PLoS One 6(11):e27128.

Liu Y, Baleriaux D, Kavec M, Metens T, Absil J, Denolin V, Pardou A, Avni F, Van Bogaert P, Aeby A. 2010. Structural asymmetries in motor and language networks in a population of healthy preterm neonates at term equivalent age: a diffusion tensor imaging and probabilistic tractography study. Neuroimage 51(2):783-8.

Lodygensky GA, Marques JP, Maddage R, Perroud E, Sizonenko SV, Huppi PS, Gruetter R. 2012. In vivo assessment of myelination by phase imaging at high magnetic field. Neuroimage 59(3):1979-87.

Maas LC, Mukherjee P, Carballido-Gamio J, Veeraraghavan S, Miller SP, Partridge SC, Henry RG, Barkovich AJ, Vigneron DB. 2004. Early laminar organization of the human cerebrum demonstrated with diffusion tensor imaging in extremely premature infants. Neuroimage 22(3):1134-40.

Mahmoudzadeh M, Dehaene-Lambertz G, Fournier M, Kongolo G, Goudjil S, Dubois J, Grebe R, Wallois F. 2013. Syllabic discrimination in premature human infants prior to complete formation of cortical layers. Proc Natl Acad Sci U S A 110(12):4846-51.

Maldonado IL, de Champfleur NM, Velut S, Destrieux C, Zemmoura I, Duffau H. 2013. Evidence of a middle longitudinal fasciculus in the human brain from fiber dissection. $\mathrm{J}$ Anat.

Martino J, Brogna C, Robles SG, Vergani F, Duffau H. 2010. Anatomic dissection of the inferior fronto-occipital fasciculus revisited in the lights of brain stimulation data. Cortex 46(5):691-9.

Matsumae M, Kurita D, Atsumi H, Haida M, Sato O, Tsugane R. 2001. Sequential changes in MR water proton relaxation time detect the process of rat brain myelination during maturation. Mech Ageing Dev 122(12):1281-91. 
Matsuzawa J, Matsui M, Konishi T, Noguchi K, Gur RC, Bilker W, Miyawaki T. 2001. Agerelated volumetric changes of brain gray and white matter in healthy infants and children. Cereb Cortex 11(4):335-42.

Matthieu JM. 1993. An introduction to the molecular basis of inherited myelin diseases. J Inherit Metab Dis 16(4):724-32.

McCart RJ, Henry GH. 1994. Visual corticogeniculate projections in the cat. Brain Res 653(12):351-6.

McConnell SK, Ghosh A, Shatz CJ. 1989. Subplate neurons pioneer the first axon pathway from the cerebral cortex. Science 245(4921):978-82.

McCulloch DL, Orbach H, Skarf B. 1999. Maturation of the pattern-reversal VEP in human infants: a theoretical framework. Vision Res 39(22):3673-80.

McGowan JC. 1999. The physical basis of magnetization transfer imaging. Neurology 53(5 Suppl 3):S3-7.

McGraw P, Liang L, Provenzale JM. 2002. Evaluation of normal age-related changes in anisotropy during infancy and childhood as shown by diffusion tensor imaging. AJR Am J Roentgenol 179(6):1515-22.

McKinstry RC, Mathur A, Miller JH, Ozcan A, Snyder AZ, Schefft GL, Almli CR, Shiran SI, Conturo TE, Neil JJ. 2002. Radial organization of developing preterm human cerebral cortex revealed by non-invasive water diffusion anisotropy MRI. Cereb Cortex 12(12):1237-43.

Menon RS, Rusinko MS, Allen PS. 1991. Multiexponential proton relaxation in model cellular systems. Magn Reson Med 20(2):196-213.

Ment LR, Hirtz D, Huppi PS. 2009. Imaging biomarkers of outcome in the developing preterm brain. Lancet Neurol 8(11):1042-55.

Mewes AU, Huppi PS, Als H, Rybicki FJ, Inder TE, McAnulty GB, Mulkern RV, Robertson RL, Rivkin MJ, Warfield SK. 2006. Regional brain development in serial magnetic resonance imaging of low-risk preterm infants. Pediatrics 118(1):23-33.

Miller DJ, Duka T, Stimpson CD, Schapiro SJ, Baze WB, McArthur MJ, Fobbs AJ, Sousa AM, Sestan N, Wildman DE and others. 2012. Prolonged myelination in human neocortical evolution. Proc Natl Acad Sci U S A 109(41):16480-5.

Miller SP, Vigneron DB, Henry RG, Bohland MA, Ceppi-Cozzio C, Hoffman C, Newton N, Partridge JC, Ferriero DM, Barkovich AJ. 2002. Serial quantitative diffusion tensor MRI of the premature brain: development in newborns with and without injury. $\mathbf{J}$ Magn Reson Imaging 16(6):621-32.

Mukherjee P, Miller JH, Shimony JS, Conturo TE, Lee BC, Almli CR, McKinstry RC. 2001. Normal brain maturation during childhood: developmental trends characterized with diffusion-tensor MR imaging. Radiology 221(2):349-58.

Mukherjee P, Miller JH, Shimony JS, Philip JV, Nehra D, Snyder AZ, Conturo TE, Neil JJ, McKinstry RC. 2002. Diffusion-tensor MR imaging of gray and white matter development during normal human brain maturation. AJNR Am J Neuroradiol 23(9):1445-56.

Neil J, Miller J, Mukherjee P, Huppi PS. 2002. Diffusion tensor imaging of normal and injured developing human brain - a technical review. NMR Biomed 15(7-8):543-52.

Neil JJ, Shiran SI, McKinstry RC, Schefft GL, Snyder AZ, Almli CR, Akbudak E, Aronovitz JA, Miller JP, Lee BC and others. 1998. Normal brain in human newborns: apparent diffusion coefficient and diffusion anisotropy measured by using diffusion tensor MR imaging. Radiology 209(1):57-66.

Ng WP, Cartel N, Roder J, Roach A, Lozano A. 1996. Human central nervous system myelin inhibits neurite outgrowth. Brain Res 720(1-2):17-24. 
Nossin-Manor R, Card D, Morris D, Noormohamed S, Shroff MM, Whyte HE, Taylor MJ, Sled JG. 2012. Quantitative MRI in the very preterm brain: assessing tissue organization and myelination using magnetization transfer, diffusion tensor and $\mathrm{T}(1)$ imaging. Neuroimage.

O'Muircheartaigh J, Dean DC, 3rd, Dirks H, Waskiewicz N, Lehman K, Jerskey BA, Deoni SC. 2013. Interactions between White Matter Asymmetry and Language during Neurodevelopment. J Neurosci 33(41):16170-16177.

Oishi K, Mori S, Donohue PK, Ernst T, Anderson L, Buchthal S, Faria A, Jiang H, Li X, Miller MI and others. 2011. Multi-contrast human neonatal brain atlas: application to normal neonate development analysis. Neuroimage 56(1):8-20.

Pandit AS, Robinson E, Aljabar P, Ball G, Gousias IS, Wang Z, Hajnal JV, Rueckert D, Counsell SJ, Montana G and others. 2013. Whole-Brain Mapping of Structural Connectivity in Infants Reveals Altered Connection Strength Associated with Growth and Preterm Birth. Cereb Cortex.

Parker GJ, Luzzi S, Alexander DC, Wheeler-Kingshott CA, Ciccarelli O, Lambon Ralph MA. 2005. Lateralization of ventral and dorsal auditory-language pathways in the human brain. Neuroimage 24(3):656-66.

Partridge SC, Mukherjee P, Berman JI, Henry RG, Miller SP, Lu Y, Glenn OA, Ferriero DM, Barkovich AJ, Vigneron DB. 2005. Tractography-based quantitation of diffusion tensor imaging parameters in white matter tracts of preterm newborns. J Magn Reson Imaging 22(4):467-74.

Partridge SC, Mukherjee P, Henry RG, Miller SP, Berman JI, Jin H, Lu Y, Glenn OA, Ferriero DM, Barkovich AJ and others. 2004. Diffusion tensor imaging: serial quantitation of white matter tract maturity in premature newborns. Neuroimage 22(3):1302-14.

Paus T. 2005. Mapping brain maturation and cognitive development during adolescence. Trends Cogn Sci 9(2):60-8.

Paus T. 2010. Growth of white matter in the adolescent brain: myelin or axon? Brain Cogn 72(1):26-35

Paus T, Collins DL, Evans AC, Leonard G, Pike B, Zijdenbos A. 2001. Maturation of white matter in the human brain: a review of magnetic resonance studies. Brain Res Bull 54(3):255-66.

Paus T, Zijdenbos A, Worsley K, Collins DL, Blumenthal J, Giedd JN, Rapoport JL, Evans AC. 1999. Structural maturation of neural pathways in children and adolescents: in vivo study. Science 283(5409):1908-11.

Perani D, Saccuman MC, Scifo P, Anwander A, Spada D, Baldoli C, Poloniato A, Lohmann G, Friederici AD. 2011. Neural language networks at birth. Proc Natl Acad Sci U S A 108(38):16056-61.

Peterson BS, Anderson AW, Ehrenkranz R, Staib LH, Tageldin M, Colson E, Gore JC, Duncan CC, Makuch R, Ment LR. 2003. Regional brain volumes and their later neurodevelopmental correlates in term and preterm infants. Pediatrics 111(5 Pt 1):93948.

Poduslo SE, Jang Y. 1984. Myelin development in infant brain. Neurochem Res 9(11):161526.

Pontabry J, Rousseau F, Oubel E, Studholme C, Koob M, Dietemann JL. 2013. Probabilistic tractography using Q-ball imaging and particle filtering: Application to adult and inutero fetal brain studies. Med Image Anal.

Prastawa M, Sadeghi N, Gilmore J, Lin W, Gerig G. 2010. A new framework for analyzing white matter maturation in early brain development. Proceedings of the 22nd IPMI meeting. 
Prayer D, Barkovich AJ, Kirschner DA, Prayer LM, Roberts TP, Kucharczyk J, Moseley ME. 2001. Visualization of nonstructural changes in early white matter development on diffusion-weighted MR images: evidence supporting premyelination anisotropy. AJNR Am J Neuroradiol 22(8):1572-6.

Prayer D, Prayer L. 2003. Diffusion-weighted magnetic resonance imaging of cerebral white matter development. Eur J Radiol 45(3):235-43.

Pujol J, Soriano-Mas C, Ortiz H, Sebastian-Galles N, Losilla JM, Deus J. 2006. Myelination of language-related areas in the developing brain. Neurology 66(3):339-43.

Rados M, Judas M, Kostovic I. 2006. In vitro MRI of brain development. Eur J Radiol 57(2):187-98.

Righini A, Bianchini E, Parazzini C, Gementi P, Ramenghi L, Baldoli C, Nicolini U, Mosca F, Triulzi F. 2003. Apparent diffusion coefficient determination in normal fetal brain: a prenatal MR imaging study. AJNR Am J Neuroradiol 24(5):799-804.

Rose SE, Hatzigeorgiou X, Strudwick MW, Durbridge G, Davies PS, Colditz PB. 2008. Altered white matter diffusion anisotropy in normal and preterm infants at termequivalent age. Magn Reson Med 60(4):761-7.

Rutherford MA, Supramaniam V, Ederies A, Chew A, Bassi L, Groppo M, Anjari M, Counsell S, Ramenghi LA. 2010. Magnetic resonance imaging of white matter diseases of prematurity. Neuroradiology 52(6):505-21.

Sadeghi N, Prastawa M, Fletcher PT, Wolff J, Gilmore JH, Gerig G. 2013. Regional characterization of longitudinal DT-MRI to study white matter maturation of the early developing brain. Neuroimage.

Salami M, Itami C, Tsumoto T, Kimura F. 2003. Change of conduction velocity by regional myelination yields constant latency irrespective of distance between thalamus and cortex. Proc Natl Acad Sci U S A 100(10):6174-9.

Scott JA, Habas PA, Kim K, Rajagopalan V, Hamzelou KS, Corbett-Detig JM, Barkovich AJ, Glenn OA, Studholme C. 2011. Growth trajectories of the human fetal brain tissues estimated from 3D reconstructed in utero MRI. Int J Dev Neurosci 29(5):529-36.

Short SJ, Elison JT, Goldman BD, Styner M, Gu H, Connelly M, Maltbie E, Woolson S, Lin W, Gerig G and others. 2013. Associations between white matter microstructure and infants' working memory. Neuroimage 64:156-66.

Sowell ER, Thompson PM, Rex D, Kornsand D, Tessner KD, Jernigan TL, Toga AW. 2002. Mapping sulcal pattern asymmetry and local cortical surface gray matter distribution in vivo: maturation in perisylvian cortices. Cereb Cortex 12(1):17-26.

Spader HS, Ellermeier A, O'Muircheartaigh J, Dean DC, 3rd, Dirks H, Boxerman JL, Cosgrove GR, Deoni SC. 2013. Advances in myelin imaging with potential clinical application to pediatric imaging. Neurosurg Focus 34(4):E9.

Stiles J, Jernigan TL. 2010. The basics of brain development. Neuropsychol Rev 20(4):32748.

Su P, Kuan CC, Kaga K, Sano M, Mima K. 2008. Myelination progression in languagecorrelated regions in brain of normal children determined by quantitative MRI assessment. Int J Pediatr Otorhinolaryngol 72(12):1751-63.

Takahashi E, Folkerth RD, Galaburda AM, Grant PE. 2012. Emerging cerebral connectivity in the human fetal brain: an MR tractography study. Cereb Cortex 22(2):455-64.

Tauber H, Waehneldt TV, Neuhoff V. 1980. Myelination in rabbit optic nerves is accelerated by artificial eye opening. Neurosci Lett 16(3):235-8.

Thomas JL, Spassky N, Perez Villegas EM, Olivier C, Cobos I, Goujet-Zalc C, Martinez S, Zalc B. 2000. Spatiotemporal development of oligodendrocytes in the embryonic brain. J Neurosci Res 59(4):471-6. 
Thompson DK, Inder TE, Faggian N, Warfield SK, Anderson PJ, Doyle LW, Egan GF. 2012. Corpus callosum alterations in very preterm infants: perinatal correlates and 2 year neurodevelopmental outcomes. Neuroimage 59(4):3571-81.

Toga AW, Thompson PM. 2003. Mapping brain asymmetry. Nat Rev Neurosci 4(1):37-48.

Travis KE, Curran MM, Torres C, Leonard MK, Brown TT, Dale AM, Elman JL, Halgren E. 2013. Age-related Changes in Tissue Signal Properties Within Cortical Areas Important for Word Understanding in 12- to 19-Month-Old Infants. Cereb Cortex.

van Buchem MA, Steens SC, Vrooman HA, Zwinderman AH, McGowan JC, Rassek M, Engelbrecht V. 2001. Global estimation of myelination in the developing brain on the basis of magnetization transfer imaging: a preliminary study. AJNR Am J Neuroradiol 22(4):762-6.

van der Knaap MS, Valk J. 1990. MR imaging of the various stages of normal myelination during the first year of life. Neuroradiology 31(6):459-70.

Van der Knaap MS, Valk J. 1995. Myelin and white matter. Magnetic resonance of myelin, myelination and myelin disorders, Van der Knaap MS and Valk J eds, SpringerVerlag, Berlin:1-17.

Van der Knaap MS, Valk J. 1995b. Myelination and retarded myelination. Magnetic resonance of myelin, myelination and myelin disorders, Van der Knaap MS and Valk J eds, Springer-Verlag, Berlin.

van der Knaap MS, Valk J, Bakker CJ, Schooneveld M, Faber JA, Willemse J, Gooskens RH. 1991. Myelination as an expression of the functional maturity of the brain. Dev Med Child Neurol 33(10):849-57.

Volpe JJ. 2008. Neuronal Proliferation, Migration, Organization, and Myelination. Neurology of the Newborn. Saunders, Elsevier, Inc, Philadelphia.:51-118.

Whittall KP, MacKay AL, Graeb DA, Nugent RA, Li DK, Paty DW. 1997. In vivo measurement of T2 distributions and water contents in normal human brain. Magn Reson Med 37(1):34-43.

Williams LA, Gelman N, Picot PA, Lee DS, Ewing JR, Han VK, Thompson RT. 2005. Neonatal brain: regional variability of in vivo MR imaging relaxation rates at $3.0 \mathrm{~T}$-initial experience. Radiology 235(2):595-603.

Wimberger DM, Roberts TP, Barkovich AJ, Prayer LM, Moseley ME, Kucharczyk J. 1995. Identification of "premyelination" by diffusion-weighted MRI. J Comput Assist Tomogr 19(1):28-33.

Xu G, Takahashi E, Folkerth RD, Haynes RL, Volpe JJ, Grant PE, Kinney HC. 2012. Radial Coherence of Diffusion Tractography in the Cerebral White Matter of the Human Fetus: Neuroanatomic Insights. Cereb Cortex.

Xydis V, Astrakas L, Zikou A, Pantou K, Andronikou S, Argyropoulou MI. 2006. Magnetization transfer ratio in the brain of preterm subjects: age-related changes during the first 2 years of life. Eur Radiol 16(1):215-20.

Yakovlev PI. 1962. Morphological criteria of growth and maturation of the nervous system in man. Res Publ Assoc Res Nerv Ment Dis 39:3-46.

Yakovlev PI, Lecours AR. 1967. The myelogenetic cycles of regional maturation in the brain. In: Regional development of the brain in early life Minowski A. eds, Blackwell, Oxford:3-69.

Yap PT, Fan Y, Chen Y, Gilmore JH, Lin W, Shen D. 2011. Development trends of white matter connectivity in the first years of life. PLoS One 6(9):e24678.

Yendiki A, Panneck P, Srinivasan P, Stevens A, Zöllei L, Augustinack J, Wang R, Salat D, Ehrlich S, Behrens T and others. 2011. Automated probabilistic reconstruction of white-matter pathways in health and disease using an atlas of the underlying anatomy. Front Neuroinform:5:23. 
Yoshida S, Oishi K, Faria AV, Mori S. 2013. Diffusion tensor imaging of normal brain development. Pediatr Radiol 43(1):15-27.

Zanin E, Ranjeva JP, Confort-Gouny S, Guye M, Denis D, Cozzone PJ, Girard N. 2011. White matter maturation of normal human fetal brain. An in vivo diffusion tensor tractography study. Brain Behav 1(2):95-108.

Zhang J, Evans A, Hermoye L, Lee SK, Wakana S, Zhang W, Donohue P, Miller MI, Huang H, Wang X and others. 2007. Evidence of slow maturation of the superior longitudinal fasciculus in early childhood by diffusion tensor imaging. Neuroimage 38(2):239-47.

Zhong K, Ernst T, Buchthal S, Speck O, Anderson L, Chang L. 2011. Phase contrast imaging in neonates. Neuroimage 55(3):1068-72. 